Article

\title{
Doppler Aerosol WiNd (DAWN) Lidar during CPEX 2017: Instrument Performance and Data Utility
}

\author{
Steven Greco ${ }^{1, * \mathbb{C}}$, George D. Emmitt ${ }^{1}$, Michael Garstang ${ }^{1}$ and Michael Kavaya ${ }^{2}$ \\ 1 Simpson Weather Associates, Charlottesville, VA 22902, USA; gde@swa.com (G.D.E.); mxg@swa.com (M.G.) \\ 2 NASA Langley Research Center, Hampton, VA 23681, USA; michael.j.kavaya@nasa.gov \\ * Correspondence: sxg@swa.com; Tel.: +1-434-979-3571
}

Received: 8 August 2020; Accepted: 5 September 2020; Published: 11 September 2020

check for

updates

\begin{abstract}
During 25 May-24 June 2017, NASA's Doppler Aerosol WiNd (DAWN) lidar was flown on board a NASA DC-8 aircraft as part of the Convective Processes EXperiment (CPEX) airborne campaign based out of Ft. Lauderdale, FL. Central to DAWN's deployment was the goal of obtaining high time and spatial resolution wind velocity measurements, particularly with respect to the convective life cycle. We describe the processes involved in deriving wind profiles from DAWN observations and evaluate the performance of DAWN in terms of data coverage, resolution and frequency. Comparisons with dropsonde wind measurements show an overall low bias of $<0.20 \mathrm{~m} / \mathrm{s}$ with a RMSD of $\sim 1.6$ and $\mathrm{R}^{2}>0.92$ for both $\mathrm{u}$ and $\mathrm{v}$ components for the data set as a whole (over 160 comparisons). From this CPEX experience, we find that the DAWN wind profiles are of high precision, $\sim 30 \mathrm{~m}$ vertical resolution and with horizontal spacing as fine as $3-7 \mathrm{~km}$, and rival dropsondes for horizontal wind coverage (aerosols and clouds permitting). Case studies illustrate the benefit of using the DAWN to investigate and characterize the dynamics of the tropical atmosphere over open ocean waters in conditions ranging from undisturbed to active convection.
\end{abstract}

Keywords: airborne doppler wind lidar; coherent; winds; wind profiles; DAWN; marine boundary layer; CPEX; convection

\section{Introduction}

During 25 May-24 June 2017, NASA conducted the Convective Processes EXperiment (CPEX) airborne field campaign based out of Ft. Lauderdale, FL to investigate the atmospheric environment and convective cloud life cycles over the western North Atlantic-Gulf of Mexico-Caribbean Oceanic region. A main objective was to obtain a comprehensive set of simultaneous wind, temperature, and moisture profiles over the tropical waters during convective and non-convective conditions that could be used in process and modeling studies of convective and boundary layer processes over the tropical oceans. To meet this and other objectives, NASA selected a suite of instruments to be flown on a NASA DC-8 aircraft during CPEX. These instruments included the featured instrument of the campaign, NASA LaRC's Doppler Aerosol WiNd (DAWN) lidar [1], plus the Yankee Environmental Services (YES) High Definition Sounding System (HDSS)/eXpendable Digital Dropsondes (XDD) [2], and four instruments from NASA JPL: the airborne second generation precipitation radar (APR-2) [3], the High Altitude MMIC Sounding Radiometer (HAMSR) [4], the Microwave Temperature and Humidity Profiler (MTHP) [5], and the Microwave Atmospheric Sounder for Cubesat (MASC) [6].

Previous studies have shown that lidar systems can be of particular utility to the understanding of convective cloud initiation and evolution and modeling over the open tropical ocean [7-9]. Many of the ongoing CPEX research studies are near completion but the impact of DAWN wind profiles on the numerical simulation of tropical convective systems has already been documented [10] while complementary wind data from DAWN (in mostly clear and high aerosol conditions) and APR-2 (clouds 
and rain) have been used together to describe the structure of convective systems [11]. A number of other studies are also utilizing the DAWN data in their modeling and science investigations. With this as a motivation, the purpose of this paper is to provide a brief description of the DAWN lidar and data products as well as a review of the performance of DAWN during CPEX. This includes not only the performance of the instrument itself, but also the steps taken and the challenges faced in the processing of the raw DAWN data, and the resulting resolution, coverage, frequency, and comparison of the processed DAWN wind data with other wind measurements.

Special importance is focused upon the performance and data coverage of DAWN in the Marine Atmospheric Boundary Layer (MABL) in both undisturbed and cloudy/convective environments as well as both strong and weak aerosol situations. In addition, examples of the utilization of the high resolution (3-20 km in the horizontal and 30-150 $\mathrm{m}$ in the vertical) DAWN data to describe the dynamic structure of the tropical atmosphere over selected convective or non-convective environments are also presented.

\section{Field Campaign}

The CPEX campaign included 16 missions over the western tropical Atlantic Ocean, Caribbean Sea, and the Gulf of Mexico (GoM) to investigate the atmosphere and convection, ranging from undisturbed conditions to scattered convection and to organized convection at various stages of the convective cloud life cycle. Figure 1 presents the location of all flight tracks during CPEX while Table 1 provides the details of each individual mission along with information on the dropsondes. The resulting data from these missions have provided a unique set of wind, temperature, and humidity profiles to be used in analysis, model assimilation, and prediction studies.

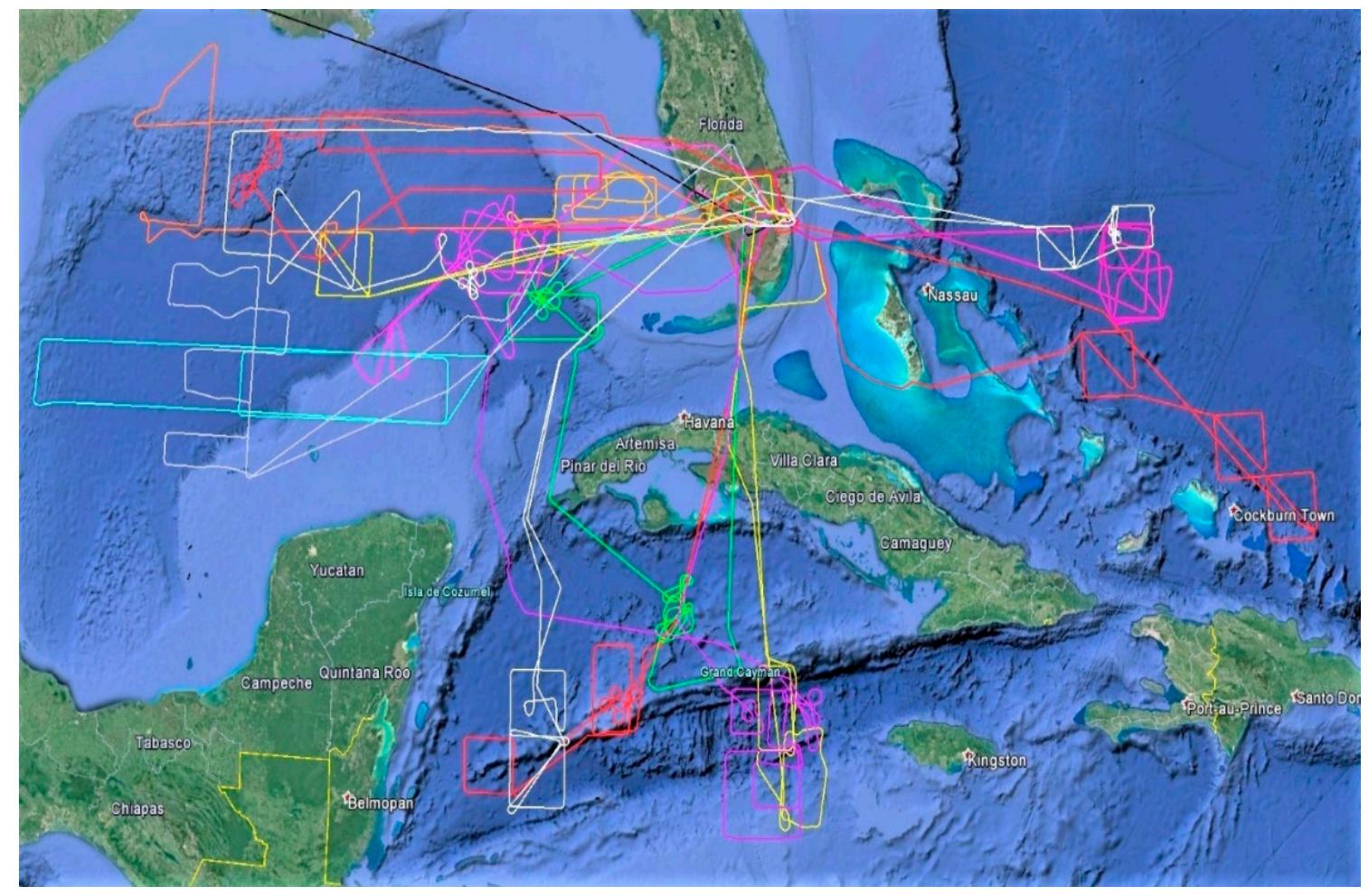

Figure 1. Location of sixteen flight missions during the 2017 CPEX field campaign (Google Earth). 
Table 1. Summary of the CPEX flight missions for DAWN and other instruments. Number of XDD dropsondes used in comparisons is noted in parentheses.

\begin{tabular}{cccccc}
\hline Mission & Location Focus & $\begin{array}{c}\text { Vertical } \\
\text { Extent }\end{array}$ & $\begin{array}{c}\text { DAWN } \\
\text { Hor. Res. }\end{array}$ & $\begin{array}{c}\text { Number of } \\
\text { XDD }\end{array}$ & Atmospheric Environment \\
\hline 27 May & GoM & $7-8 \mathrm{~km}$ & $3-7 \mathrm{~km}$ & $9(9)$ & undisturbed \\
\hline 29 May & Caribbean Sea & $8-9 \mathrm{~km}$ & $5-7 \mathrm{~km}$ & $15(13)$ & scattered. shallow convection \\
\hline 31 May & $\begin{array}{c}\text { east of } \\
\text { Bahamas }\end{array}$ & $9-10 \mathrm{~km}$ & $10-15 \mathrm{~km}$ & $16(13)$ & scattered/isolated convection \\
\hline 1 June & eastern GoM & $12 \mathrm{~km}$ & $7-15 \mathrm{~km}$ & $21(13)$ & organized convection \\
\hline 2 June & GoM & $12 \mathrm{~km}$ & $5-10 \mathrm{~km}$ & $19(17)$ & convection \\
\hline 6 June & eastern GoM & $9 \mathrm{~km}$ & $7-10 \mathrm{~km}$ & $7(6)$ & undisturbed west; convection east \\
\hline 10 June & $\begin{array}{c}\text { east of } \\
\text { Bahamas }\end{array}$ & $9-10 \mathrm{~km}$ & $4-6 \mathrm{~km}$ & $26(14)$ & targeted mesoscale cluster \\
\hline 11 June & Central GoM & $8-10 \mathrm{~km}$ & $7-10 \mathrm{~km}$ & $28(14)$ & organized convection and inflow \\
\hline 15 June & Caribbean Sea & $10 \mathrm{~km}$ & $4-7 \mathrm{~km}$ & $9(4)$ & active convection \\
\hline 16 June & Caribbean Sea & $10 \mathrm{~km}$ & $10-15 \mathrm{~km}$ & $28(12)$ & convection \\
\hline 17 June & Caribbean Sea & $9-12 \mathrm{~km}$ & $7-10 \mathrm{~km}$ & $20(\mathrm{NA})$ & convection \\
\hline 19 June & GoM & $12 \mathrm{~km}$ & $3-15 \mathrm{~km} ;$ & $19(8)$ & convection; precursor TS Cindy \\
\hline 20 June & central GoM & $10-12 \mathrm{~km}$ & $9-12 \mathrm{~km}$ & $16(12)$ & TS Cindy; convective and inflow \\
\hline 21 June & Northern GoM & $4-12 \mathrm{~km}$ & $9-12 \mathrm{~km}$ & $30(22)$ & TS Cindy (southern inflow) \\
\hline 23 June & $\begin{array}{c}\text { east of } \\
\text { Bahamas }\end{array}$ & $7 \mathrm{~km}$ & $10-20 \mathrm{~km} ;$ & $7(6)$ & undisturbed/isolated convection \\
\hline Caribbean Sea & $10-12 \mathrm{~km}$ & $10-20 \mathrm{~km} ;$ & $9(\mathrm{NA})$ & undisturbed and convection \\
\hline
\end{tabular}

\section{The DAWN Instrument and Wind Data Retrieval Methods}

\subsection{DAWN Instrument Description}

The DAWN airborne doppler wind lidar (ADWL) and its pulsed 2-micron laser were both designed and built at NASA Langley Research Center (LaRC) $[1,12,13]$. The 250-mJ pulse energy is the largest energy in an airborne coherent wind lidar today.

DAWN employs coherent detection of backscattered light from airborne aerosols which results in both excellent wind velocity accuracy and high photon (electrical) efficiency. A refractive wedge scanner at the bottom of the airplane deflects the $15-\mathrm{cm}$ diameter transmitted laser beam by 30 degrees from nadir. Computer controlled motor rotation of the wedge permits step-stare laser shot integration at up to 12 azimuth or line-of-sight (LOS) angles. Figure 2 shows the DAWN instrument as installed on the NASA DC-8 for CPEX.

Some key laser and lidar parameters of DAWN are listed in Table 2. The combination of coherent detection, the capture of the entire signal spectrum into a computer, and frequency (or tone) estimation creates two important wind measurement figures of merit (FOM): the velocity estimate accuracy and the percentage of measurements that produce a wind estimate related to the true wind (i.e., successful) and not an outlier. This latter FOM is the most important since all successful ADWL measurements have excellent accuracy. Once a successful percentage goal is set, e.g., $90 \%$, the minimum aerosol backscatter coefficient meeting the goal becomes a key parameter. This minimum value is improved by the product of the laser pulse energy, the square root of laser pulse rate, and the receiver area. 


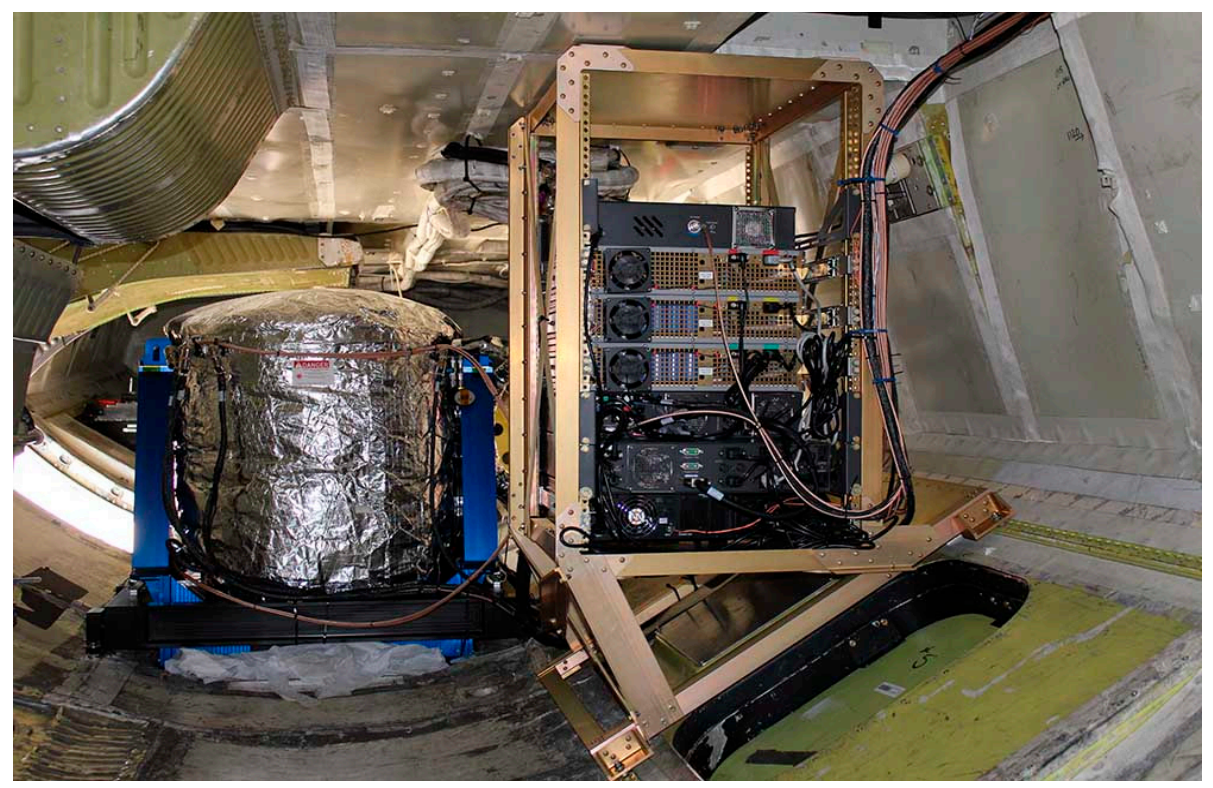

Figure 2. The DAWN instrument on board the NASA DC-8 during the 2017 CPEX.

Table 2. DAWN Lidar Specifications.

\begin{tabular}{cc}
\hline Attribute & Value \\
\hline Airplanes flown & DC-8 and UC-12B \\
\hline Solid-state laser crystal and wavelength & Ho:Tm:LuLiF, 2.053472 microns \\
\hline Laser pulse energy, rate, and FWHM duration & $250 \mathrm{~mJ}, 10 \mathrm{~Hz}, 180 \mathrm{~ns}$ \\
\hline Receiver telescope diameter & $\begin{array}{c}15 \mathrm{~cm} \text {; the transmitted laser beam is aligned for the } \\
\text { optimum (coherent detection, diffuse target) } \mathrm{e}^{-2} \text { intensity } \\
\text { diameter of } 12 \mathrm{~cm}\end{array}$ \\
\hline Scan pattern & Step-stare, 30-deg half angle conical, centered on nadir \\
\hline Number of LOS/azimuth angles & SelecTable 1, 2, 5, 8 or 12 \\
\hline Number of laser shots at each LOS & Selectable, typically 10-20 (1-2 s) \\
\hline Optical detection & Dual-balanced coherent (heterodyne), InGaAs \\
\hline Laser pointing knowledge & $\begin{array}{c}\text { Dedicated INS/GPS on lidar supplemented by } \\
\text { ground returns }\end{array}$ \\
\hline
\end{tabular}

The combination of DAWN's laser pulse energy and rate with its 15-cm diameter receiving telescope makes DAWN perhaps the most capable airborne coherent wind lidar available for atmospheric research. In this case, capability is defined as the combination of horizontal (temporal) and vertical resolution, minimum aerosol level required, successful percentage, and range to the measurement. Table 3 provides a comparison between the specifications of DAWN and two other operational or on-demand ADWLs in the US, the Office of Naval Research's Twin Otter Doppler Wind Lidar (TODWL) [14], and NOAA's P3 Doppler Wind Lidar (P3DWL) [15].

DAWN has now been deployed in five NASA airborne campaigns: CPEX 2017, the 2010 Genesis and Rapid Intensification Processes (GRIP) on the DC-8 [1], Polar Winds 1 on the UC-12B in 2014, Polar Winds 2 on the DC-8 in 2015 [16-19] and the most recent 2019 Aeolus Cal/Val Preparatory campaign based out of Palmdale, CA and Hawaii when DAWN was again flown on board the NASA DC-8 [20]. In addition to these airborne field campaigns, DAWN has also been used as a land-based system in field demonstrations to measure off-shore winds along the coast of Virginia [21,22]. 
Table 3. ADWL systems parameter summary.

\begin{tabular}{ccccc}
\hline Parameter & DAWN & TODWL & P3DWL & Comments \\
\hline Wavelength $($ microns) & 2.05 & 2.05 & 1.67 & \\
\hline Energy per pulse $(\mathrm{mJ})$ & 100 & 1 & 2 & \\
\hline Pulse rate $(\mathrm{Hz})$ & 10 & 500 & 500 & \\
\hline Pulse length $(\mathrm{m})$ & $\sim 30$ & 90 & 90 & Range resolution \\
\hline Telescope diameter $(\mathrm{m})$ & 0.15 & 0.10 & 0.10 & \\
\hline Detection type & Coherent & Coherent & Coherent & 0.5 m/s LOS precision \\
\hline Weight $(\mathrm{kg})$ & 450 & 300 & 275 & Approximate weights \\
\hline Power $($ watts $)$ & 3250 & 700 & 550 & Approximate power \\
\hline FOM ${ }^{* *}$ & 1.14 & 0.02 & 0.05 & \\
\hline ** Figure of Merit $(\mathrm{FOM})=$ Pulse energy $\times$ sqrt(pulse rate $) \times$ telescope diameter squared $\times$ optical efficiency.
\end{tabular}

\subsection{DAWN Wind Data Retrieval and Data Products}

The processing of the DAWN signal return into 3-D wind measurements with high precision, high horizontal resolution, and maximum vertical coverage builds upon nearly 30 years of experience by the authors in using ADWL to study tropospheric dynamics. The raw DAWN digitized laser signal return and navigation data (GPS/INS) from every shot within each stare angle are used to derive LOS winds and signal strength along each stare and then multiple stare angle results are used to compute the 3-dimensional wind profiles for each scan.

Given that the return signal detected by the DAWN receiver is digitized at $500 \mathrm{Mhz}$, the LOS wind velocities are derived using a fast Fourier transform (FFT) on the time series. Consequentially, the range gates for the LOS time series can be chosen to meet minimum signal to noise (SNR) thresholds where SNR is defined as the peak power of the return signal/whitened noise floor. A key step in obtaining a LOS velocity in a range gated segment of the time series is the identification of the return signal peak (hereafter referred to as the "information" peak) in the FFT frequency spectrum. In the low SNR cases, we use a Kalman filter to improve information recovery.

The DAWN LOS data products derived from the digitized raw backscattered return from aerosols/clouds include the following:

1. Range gated LOS component of the 3-D wind vector illuminated along the range gate. The length of the range gate varies from $\sim 30 \mathrm{~m}$ to $1000 \mathrm{~m}$ depending upon the strength of the backscattered signal measured as the SNR (in $\mathrm{dB}$ ). The lidar system noise is determined from the range gates that are below the surface, i.e., from times when no reflected signal is being received.

2. Range gated LOS SNR determined from the power of the "information" peak in the frequency spectrum derived for each range gate.

\subsubsection{LOS Adjustments}

Before the extraction of high utility 3-dimensional wind profiles, several corrections and shot to shot adjustments are necessary. These include the removal of LOS velocity contributions from platform motion, platform attitude, laser frequency "jitter" and time of flight variations as well as optimizing the processing in weak signal regimes and near the surface.

Accounting for aircraft speed and attitude is a critical first step in preparing the collected lidar returns for processing into LOS wind products. To remove the platform's contribution to the LOS Doppler shift, both platform motion and attitude need to be known fairly precisely. Table 4 illustrates this point by comparing DAWN with the slower and lower TODWL. The data rate on this platform motion and attitude knowledge needs to be at least $10 \mathrm{~Hz}$ so that individual shots can be corrected 
before being combined (integrated) to improve detection sensitivity and to average out wind variability on scales smaller than those of interest.

Table 4. Attitude accuracy thresholds to achieve Horizontal LOS (HLOS) velocity accuracy of $0.1 \mathrm{~m} / \mathrm{s}$ and height assignment $<10 \mathrm{~m}$ with a $30^{\circ}$ nadir scan angle. DC- 8 at $250 \mathrm{~m} / \mathrm{s}$ ground speed; Twin Otter at $50 \mathrm{~m} / \mathrm{s}$ ground speed.

\begin{tabular}{cccccc}
\hline \multirow{2}{*}{ Pointing/Accuracy } & \multicolumn{2}{c}{ DC-8 at 10 km FL } & \multicolumn{2}{c}{ Twin Otter at 1 km FL } & Comments \\
\cline { 2 - 6 } & HLOS Vel & Height & HLOS Vel & Height & $\begin{array}{c}\text { Height Errors for Layer } \\
\text { Just above the Surface }\end{array}$ \\
\hline Pitch Error (deg) & 0.03 & 0.1 & 0.13 & 1.0 & \\
\hline Roll Error (deg) & 0.14 & 0.6 & 1.0 & 6.0 & $\begin{array}{c}\text { Reference roll is } \\
\text { wings level }\end{array}$ \\
\hline Yaw Error (deg) & 0.02 & 0.0 & 0.12 & 0.0 & $\begin{array}{c}\text { Ground track heading } \\
\text { reporting error }\end{array}$ \\
\hline
\end{tabular}

A GPS/INS mounted on the DAWN instrument rack provides the platform motion and attitude information needed for removal of the platform's contribution to the measured LOS velocities. While care is taken to mount the GPS/INS unit in the rack (aligned with the aircraft "reference axes"), the physical installation cannot be assumed to be accurate enough to meet the threshold objectives illustrated in Table 4. Thus, we use ground returns in cloud free conditions (below aircraft) during constant altitude flight segments over uniform land terrain. We use the ground returns, where the wind speed is zero, to derive attitude correction factors for roll, pitch, and yaw (heading). Although the correction factors derived from the ground returns should be constant once determined, we find they can vary from one day to another. During CPEX, we found that pitch is the primary attitude correction factor that varies.

A second step in preparing the LOS samples for data product generation is the accounting for changes in the frequency and timing of the outgoing pulse. Each pulse generated by the laser is sampled before being transmitted. This sample, referred to as the monitor pulse, is processed with an FFT to obtain its frequency content. The resolution of the FFT determines the precision of this correction. However, this level of uncertainty is reduced by multiple shot integrations. The frequency of DAWN's outgoing pulse varied with a standard deviation of $3.5 \mathrm{MHz}(\sim 3.5 \mathrm{~m} / \mathrm{s})$ over the 16 CPEX missions.

The third step is to adjust the height assignment of range-gated LOS data. Once the reference datum/height is chosen, the height adjustment is made empirically by "correcting" the reported time of flight from the lidar system. The variability of the reported height of the ground is usually less than a few tens of meters. Causes of this variation include aerosol gradients just adjacent to the surface, beam pointing data from the GPS/INS, and laser pulse transmission timing.

\subsubsection{Wind Profile Retrieval and Products}

After accounting for all the issues discussed above, vertical profiles for the CPEX DAWN data are then derived from either a 2-point (90 degrees between LOS stares) or 5-point (22.50 degrees between LOS stares) with a 30-degree off nadir elevation angle plus pitch correction in all cases. During CPEX, the dwells at each stare point vary from 1-20 s based on operating mode, and the time to complete full step-stare conical scan for wind profiles ranged from $30 \mathrm{~s}$ through $\sim 2 \mathrm{~min}$.

For the default processing of the CPEX DAWN data, $76 \mathrm{~m}$ LOS range gates along each LOS are used to process the profiles. These are referred to as the "base" profiles. While the shortest possible LOS range gate for DAWN is $\sim 30 \mathrm{~m}$, we have found that a $76 \mathrm{~m}$ LOS range gate is optimum for most processing. A sliding range gate of $38 \mathrm{~m}$ is frequently used to report the wind estimates along a LOS. Thus, there is some overlap between adjacent projected layers of $\sim 33 \mathrm{~m}(33 \mathrm{~m}=\cos (30) \times 38 \mathrm{~m})$. For some studies, the range gate integration length is increased up to $1 \mathrm{~km}$ to improve the SNR of the "information" peak in the accumulated power spectrum, typically in low aerosol conditions. 
The range-gated LOS velocities processed along each look or perspective as described in Sections 3.2 and 3.2.1 are inputted into the non-linear Levenberg-Marquardt (LM) damped least-squares algorithm to solve for $\mathrm{u}$ and $\mathrm{v}$ within each scan and are comprised of representative averages taken over 2 or 5 stares and over the distance and time it takes to complete the full scan while flying at $\sim 225 \mathrm{~m} / \mathrm{s}$. It should also be noted that the LOS samples that go into the solver cover areas of the order of square kilometers and with the average vertical motion (w) assumed to be zero in the solver. These resultant base profiles provide, aerosols permitting, a wind vector every $\sim 33 \mathrm{~m}$ in the vertical for $38 \mathrm{~m}$ sliding range gates.

The quality thresholds of the base profiles are generous and allowed for noise when the signal is weak. The two quality tests set for "baseline reasonable quality" are the SNR for individual LOS products and the goodness of fit (GOF) for the vector products derived from a best fit LM solver. Table 5 provides a listing of these data measurements along with the precision and both horizontal and vertical resolution of the vertical profiles that were obtained. The development of the data processing algorithms mentioned above has resulted in high accuracy $(<0.05 \mathrm{~m} / \mathrm{s})$ in the horizontal wind component observations and high resolution of aerosol features $(<5.0 \mathrm{~m}$ in some instances). The maximum range of the DAWN varies depending on the amount of clouds and aerosols but often produced wind profiles (though not complete) from 8-12 km down to the surface. This will be discussed in Section 4 . In addition, the average strength of the SNR at each level for each LOS range gate is published as the SNR for that vector sounding. This SNR value may be used as a surrogate for aerosol concentrations. More accurately, the SNR represents the backscatter from particles (including clouds) and hard targets that is dependent upon more than just aerosol concentration (e.g., particle size and shape). An example of the base profiles of SNR, wind speed, and wind direction is provided in Figure 3.

Table 5. DAWN on NASA DC-8 measurement quality and resolutions.

\begin{tabular}{cc}
\hline LOS Wind Measurement Precision & $\sim \mathbf{1 ~ m / s}$ Bias $<\mathbf{0 . 2 5 ~ m / s}$ \\
\hline $\mathrm{u}, \mathrm{v}, \mathrm{w}$ measurement precision & $<\sim 1.5 \mathrm{~m} / \mathrm{s} ;$ bias $<0.2 \mathrm{~m} / \mathrm{s}$ \\
\hline Data product vertical resolution & $30-150 \mathrm{~m}$. , selectable in post-processing \\
\hline Horizontal resolution of each LOS wind profile & $500 \mathrm{~m}$ typical (variable with \# shots) \\
\hline Horizontal resolution of vertical profile of horizontal wind & $\begin{array}{c}3-20 \mathrm{~km} \text { (variable with \# LOS, \# shots, } \\
\text { aircraft ground speed) }\end{array}$ \\
\hline
\end{tabular}

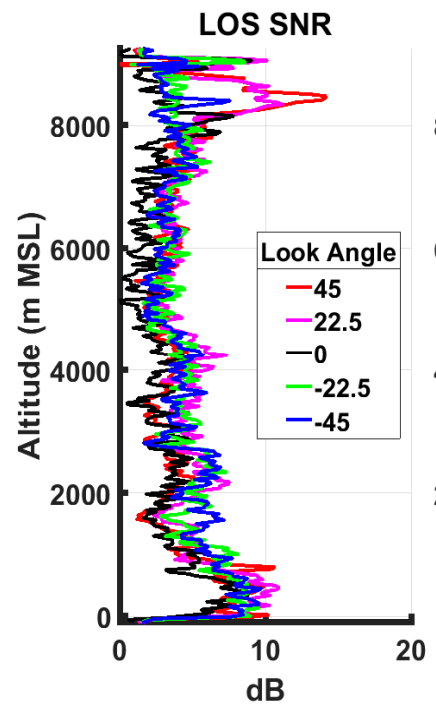

(a)

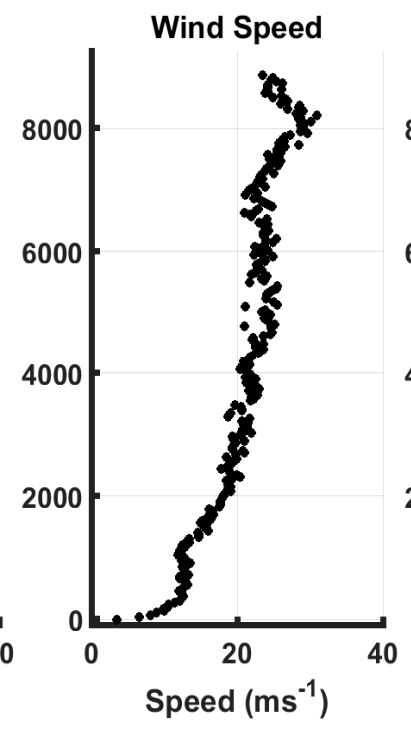

(b)

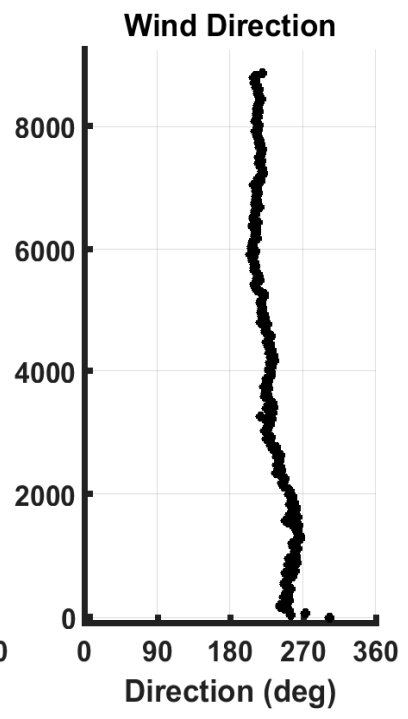

(c)

Figure 3. DAWN base vertical profiles of SNR (a), wind speed (b), and wind direction (c) on 6 June $2017204054 Z$. 


\subsubsection{Adaptive Range Gate/Shot Integration for Wind Profiles}

Every lidar has a single shot backscatter sensitivity that is a strong function of its energy per pulse, collection aperture and system optical throughput efficiency. Factors such as electronic noise, alignment, etc. are included in the optical throughput efficiency. To improve the backscatter sensitivity, a combination of shot (or sample) integration and advanced signal processing are employed. For coherent detection, sample integration implies combining either range gates along a single LOS or combining the returns from multiple shots at a given range gate, or a combination of both. The most common integration is of multiple shots depending upon the spatial and/or temporal resolution desired. In addition to the traditional shot integration, several data processing techniques have been developed that improve data recovery beyond the simple integration and maximum spectral peak detection.

As discussed at the beginning of this section, one objective of the signal processing of coherent lidar returns is to identify the "information" peak in the spectrum. Given that the information peak becomes more difficult to identify as the return signal gets weaker, means are sought to reinforce or build up the information peak by accumulating more return signal than that offered from the baseline LOS range gate of $76 \mathrm{~m}$. The options include longer range gates along individual LOS beams (shots) and accumulating returns from multiple shots in close physical proximity where "close" depends upon the aircraft speed and the natural variability of the winds on the scale of shots and range gates.

It has been a common practice to process coherent ADWL data using a fixed or set of fixed shot integrations (accumulation) and offer the best data product for the application. This approach ignores the opportunity to provide a range of ADWL product resolutions (vertical and horizontal) dictated by the backscatter and local wind variability. The adaptive sample integration algorithm (ASIA) provides a single answer to the question "what is the spatial resolution of the data?".

ASIA manages the amount of sample integration needed to get a "good" estimate of the LOS wind component. The selectable input parameters to the ASIA include:

1. Size of the "base" range gate.

2. Maximum amount of LOS integrations appropriate for the atmospheric conditions.

3. Integration lengths between the "base" range gate defined by 1 . above and the maximum length of integration defined in 2. above.

4. Threshold SNR for using a LOS integration in the LM wind vector solver.

5. Threshold GOF for accepting wind profiles obtained from the LM wind vector solver.

Figures 4 and 5 provide two examples that illustrate the vertical coverage that was very common during CPEX. The top half of the figures show the base profiles using a single range gate. This information details the atmospheric winds and the return signal strength (SNR) of DAWN. The black dots indicate where there was sufficient signal to make a wind estimate with 33-m vertical resolution as discussed above. The bottom half of Figures 4 and 5 illustrates the advantage of ASIA in the processing of the data. The color dots indicate wind values derived using various integration lengths of $265 \mathrm{~m}, 531 \mathrm{~m}, 797 \mathrm{~m}, 1063 \mathrm{~m}$, and $1329 \mathrm{~m}$. Consequently, a more complete profile is generated and the basis for editing "bad estimates" from the high-resolution product is provided. These profiles show how ASIA processing impacts both low and high wind environments as well as sheared and non-sheared cases. 

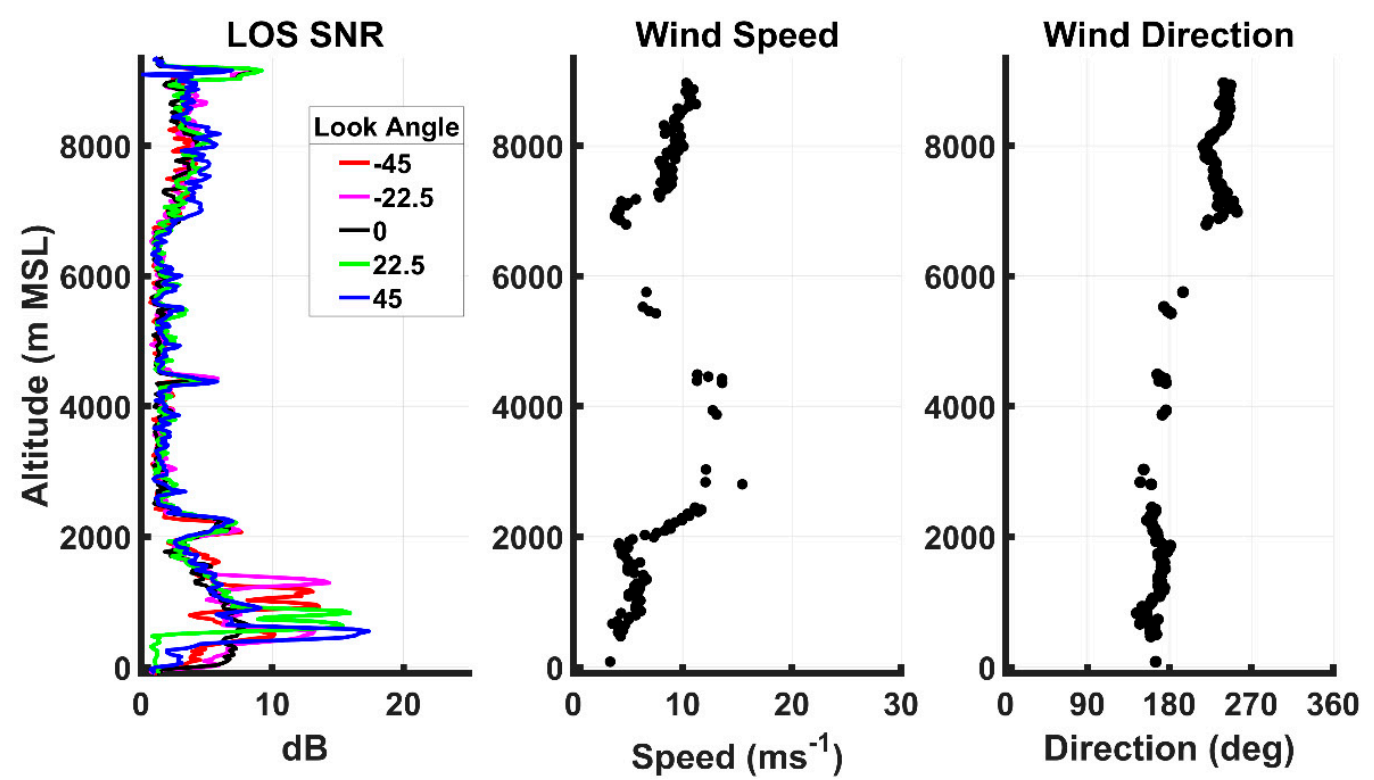

(a)
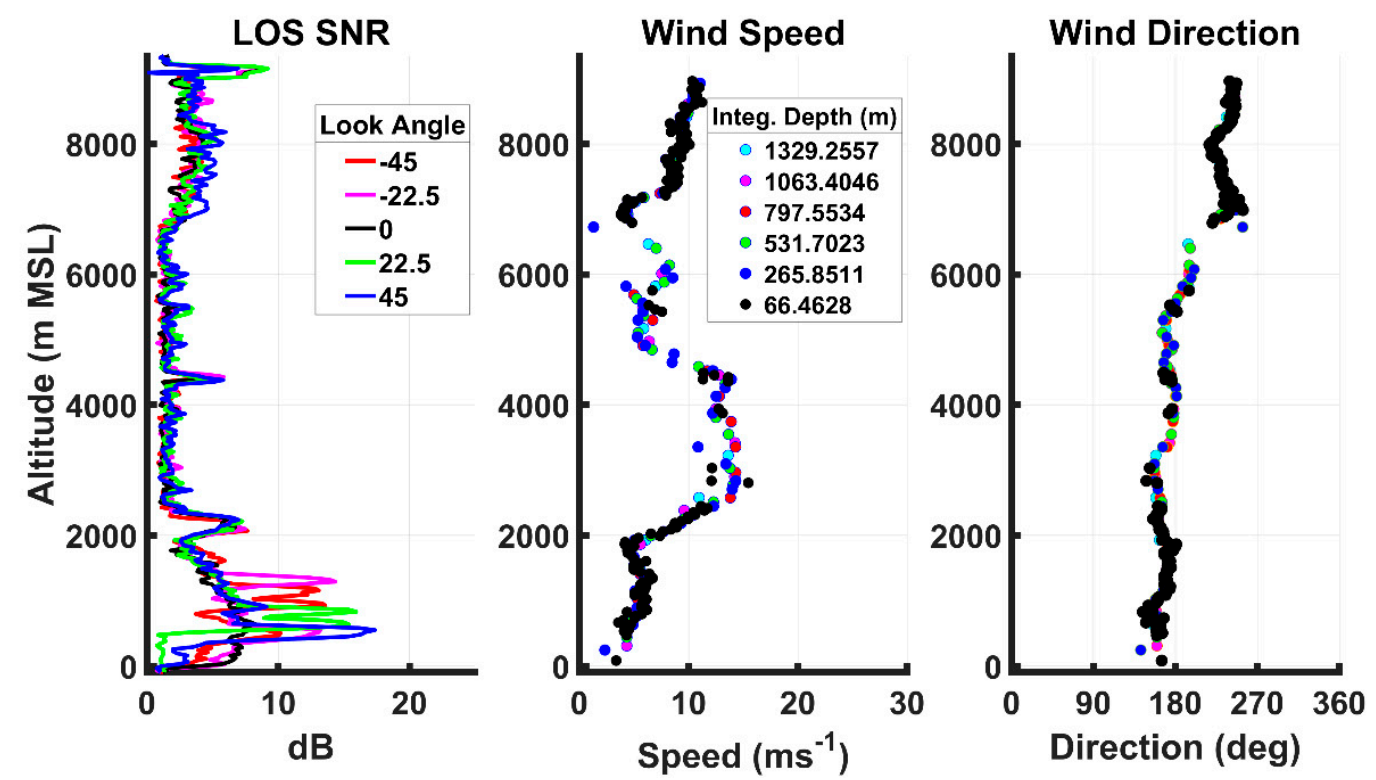

(b)

Figure 4. DAWN base vertical profiles of SNR, wind speed and wind direction processed with a single range gate (a) and adaptive integration over 5 integration depths (b) for a weak low-level wind case on 11 June $2017181034 Z$. 

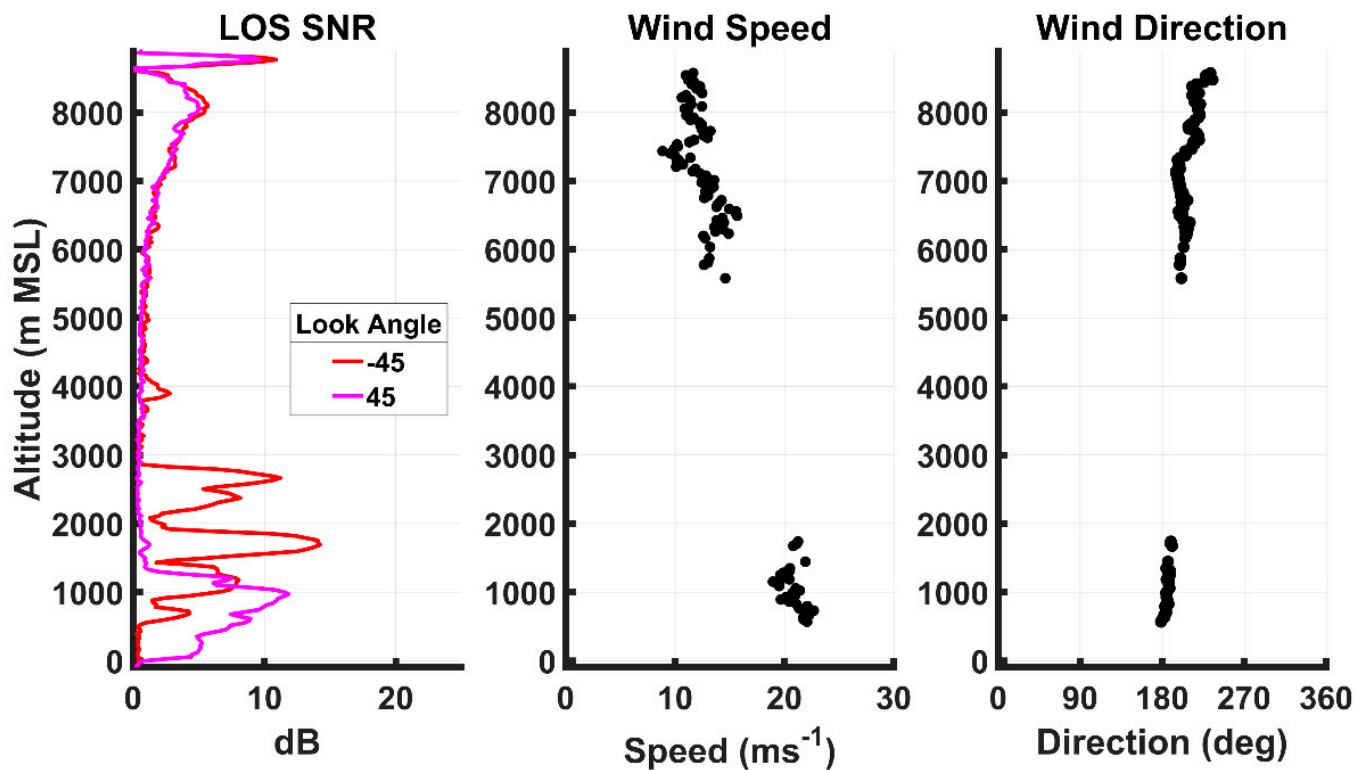

(a)
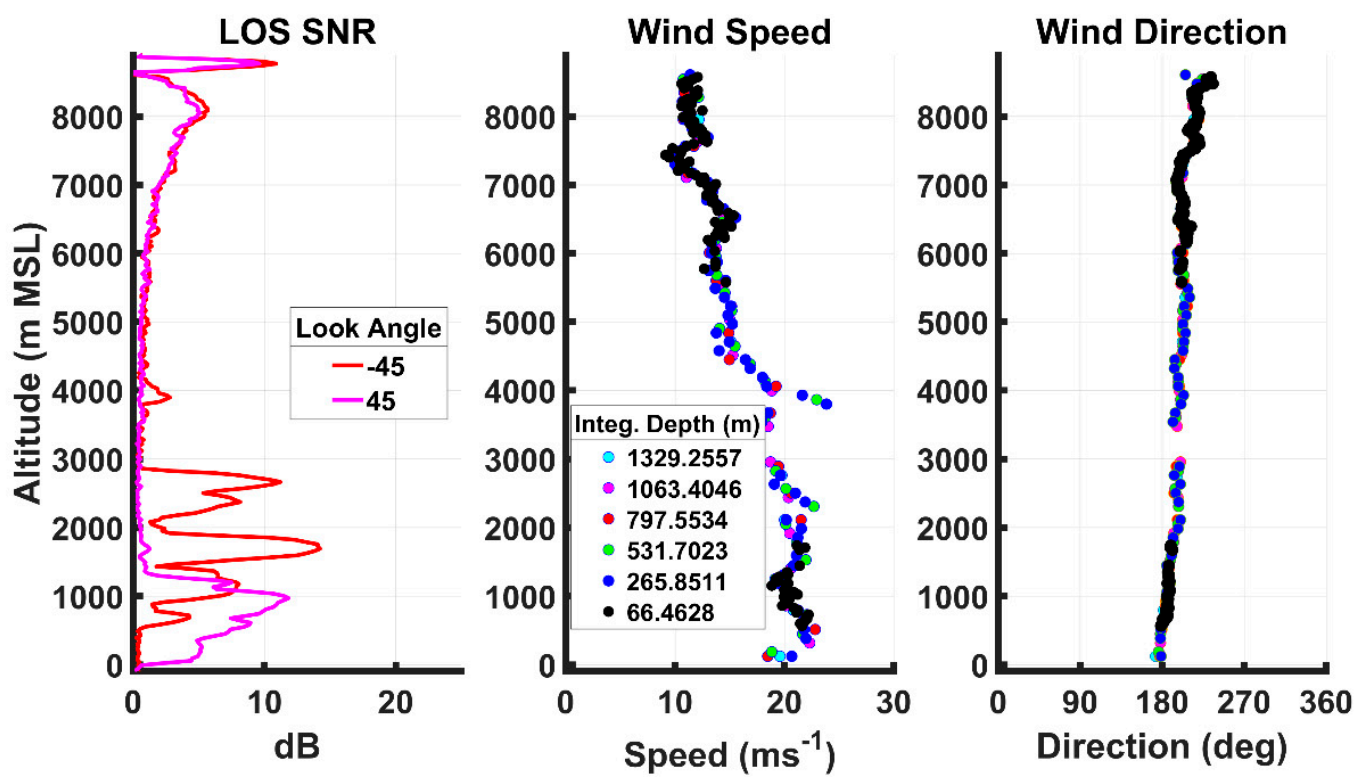

(b)

Figure 5. DAWN base vertical profiles of SNR, wind speed and wind direction processed with a single range gate (a) and adaptive integration over 5 integration depths (b) for the stronger wind case of 20 June $2017204218 Z$.

\section{Results}

\subsection{Evaluation of DAWN Performance}

As a unique, one of a kind instrument, DAWN was very reliable and available for all planned CPEX missions. It was operational at least $99 \%$ of the time between take-off and landing. There was a single field activity between missions that required technicians to open the system and optimize the beam focus. This improved the vertical coverage of the lidar but did not affect the precision of the instrument. During CPEX, occasionally DAWN did not collect useful data when the DC-8 was flying in clouds and when it descended rapidly from $>30 \mathrm{~K}$ feet to $<20 \mathrm{~K}$ feet causing the scanner window to fog temporarily. 
Depending on the speed of the DC-8 aircraft and the integration time selected for the DAWN scanner, vertical profiles of the horizontal wind were mainly attempted every $3-15 \mathrm{~km}$ in the horizontal. Occasionally, integration times and distances were set even longer in extreme low aerosol conditions and when thick clouds were attenuating the DAWN signal. The vertical extent of the wind profiles during each mission varied between 4 and $12 \mathrm{~km}$ (over water) depending on the general cloud and aerosol conditions and the objectives of each mission. Only two CPEX missions did not attempt to take measurement above $9 \mathrm{~km}$. As described in Section 3, the vertical resolution of the base DAWN vertical profile is $33 \mathrm{~m}$, although adaptive integration was also utilized over five different integration lengths to fill in gaps of missing data due to low aerosol and/or attenuated signal strength.

Table 6 provides a summary of the DAWN performance for all the CPEX missions as it relates to the successful acquisition of vertical wind profiles. These numbers only reflect the times after the DC-8 was off the Florida peninsula going outbound over the water and inbound over water before the descent back to the home base. In addition, although individual LOS data is still available for use in numerical model data assimilation, vector wind profiles during turns or excessive roll (threshold of 2.5 degrees) and during relatively rapid climbs or descents (threshold of $8 \mathrm{~m} / \mathrm{s}$ ) were not included in the official archived data due to persistent questions related to sampling under these aircraft maneuvers. In Table 6, full profiles were defined as those that provided useful wind data in $90 \%$ of all available $250 \mathrm{~m}$ layers between the aircraft and the ground.

Table 6. Outcome of Attempted DAWN Profiles during CPEX.

\begin{tabular}{ccccccc}
\hline Mission & $\begin{array}{c}\text { Profiles } \\
\text { Attempted }\end{array}$ & $\begin{array}{c}\text { Not } \\
\text { Processed } \\
\text { (Turn/Climb) }\end{array}$ & $\begin{array}{c}\text { Successful } \\
\text { Profiles }\end{array}$ & $\begin{array}{c}\text { Full } \\
\text { Profiles }\end{array}$ & $\begin{array}{c}\text { Top 2 km } \\
\text { Below DC8 }\end{array}$ & Lower 2 km \\
\hline 27 May & 320 & 39 & 281 & 155 & 267 & 277 \\
\hline 29 May & 412 & 77 & 335 & 49 & 329 & 294 \\
\hline 31 May & 232 & 35 & 197 & 2 & 185 & 180 \\
\hline 1 June & 372 & 124 & 248 & 4 & 241 & 41 \\
\hline 2 June & 583 & 58 & 525 & 0 & 508 & 52 \\
\hline 6 June & 266 & 108 & 158 & 71 & 141 & 66 \\
\hline 10 June & 540 & 138 & 402 & 36 & 376 & 174 \\
\hline 11 June & 415 & 97 & 318 & 51 & 295 & 88 \\
\hline 15 June & 422 & 100 & 322 & 15 & 291 & 86 \\
\hline 16 Jun & 119 & 23 & 96 & 7 & 94 & 55 \\
\hline 17 June & 407 & 162 & 245 & 42 & 159 & 57 \\
\hline 19 June & 354 & 58 & 296 & 2 & 258 & 10 \\
\hline 20 June & 196 & 39 & 157 & 2 & 154 & 71 \\
\hline 21 June & 430 & 113 & 317 & $105 *$ & $314 *$ & 200 \\
\hline 0-4 km & 210 & 76 & 134 & 105 & 133 & 105 \\
\hline 23 June & 747 & 179 & 568 & 119 & 549 & 498 \\
\hline 24 June & 205 & 85 & 120 & 4 & 108 & 75 \\
\hline Total & 6020 & 1435 & $4585(76 \%)$ & 664 & 4269 & $2224(48 \%)$ \\
\hline *- Part of the June 21 mission over the open water was flown at $4-4.5 \mathrm{~km}$ altitude. & \\
\hline
\end{tabular}

There were approximately $60 \mathrm{~h}$ of flight time over the open waters of the western tropical Atlantic, Caribbean Sea, and GoM during the CPEX campaign with a little over 6000 profiles attempted, or about 100 per hour on average. However, as shown in Table 6, aircraft motion in turns (flying the boxes shown in Figure 1) and climbs/descents often prevented the computation of useful wind profiles although the LOS products were retained as useful scalar samples. Despite these omissions, there 
were still almost 4600 profiles (76\%) that were successfully processed and provide reliable and useful measurements within the vertical column.

Key conclusions to be taken from Table 6 based on the performance of DAWN during the straight and level segments flown during CPEX are the following:

1. The best performance in regard to providing full profiles was, as to be expected, during undisturbed days such as 27 May, 29 May and 23 June.

2. Over $90 \%$ (4269 of 4585) of the processed DAWN base profiles on all missions provided needed measurements in the upper portions of the vertical column

3. Despite the frequent attenuation of the DAWN signal by clouds in the convective environment, almost $50 \%$ of the processed DAWN base profiles provided useful measurements in the bottom $2 \mathrm{~km}$, within or just above the MABL.

\subsection{DAWN Data Comparisons}

\subsubsection{DAWN Measured Ground Speeds}

As mentioned in Section 3, for low-level constant altitude flight segments in cloud free conditions (below the aircraft) over uniform terrain, we also made comparisons between the DAWN LOS velocities at the ground, where speed was expected to be zero, to derive attitude correction factors for pitch and yaw (heading).

The attitude corrections were determined by comparing the LOS velocity at the ground for each look angle of a scan with the value of $0 \mathrm{~m} / \mathrm{s}$, which is the "wind speed" of the ground, and iteratively finding the optimum pitch and yaw correction that minimizes the mean difference between the LOS velocities at the ground and zero. This was done for a single scan that met the conditions mentioned above and then applied to other similar profiles. Figure 6 shows the LOS velocities at the ground for each look of several 5 look scans over the peninsula of Florida at the beginning of the 27 May 2017 (three scans) and 1 June 2017 (two scans) flights. In both cases, the optimum corrections were found to be $-0.30^{\circ}$ for both pitch and yaw which resulted in mean differences between the LOS ground speed velocities and 0 ranging from -0.10 to $0.05 \mathrm{~m} / \mathrm{s}$ for the 27 May case and 0.03 to $0.08 \mathrm{~m} / \mathrm{s}$ for 1 June.

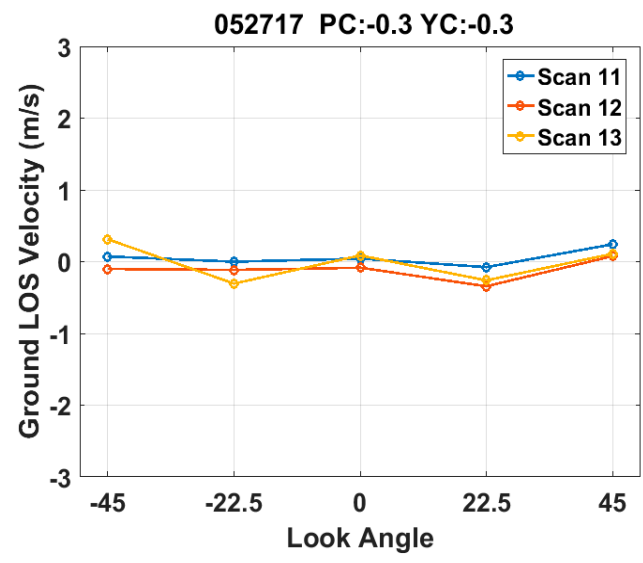

(a)

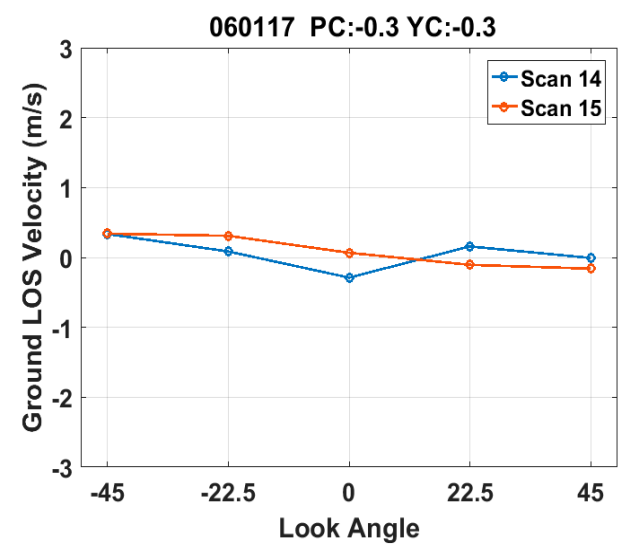

(b)

Figure 6. LOS velocities at the ground for each look of 5-look scans during cloud free constant altitude flight segments over uniform terrain of the Florida peninsula on 27 May 2017 (a) and 1 June 2017 (b).

These pitch and yaw correction factors were then used in the derivation of the wind profiles for the mission. Figure 7 shows one of the profiles that was computed during the constant level, cloud free, uniform terrain segments on, respectively, 27 May and 1 June. The maximum SNR and near zero winds at the ground of both these profiles on different days affirm the method chosen here. 


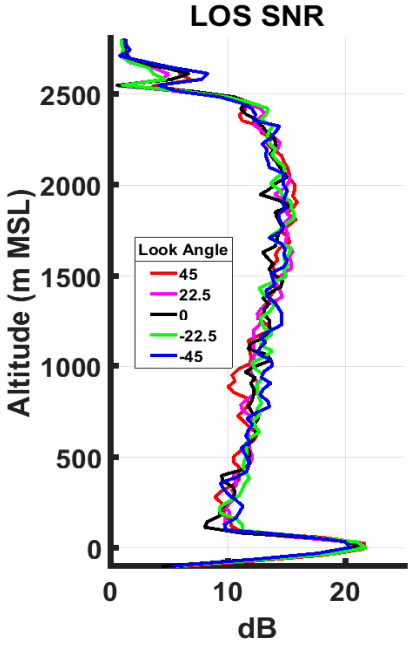

(a)

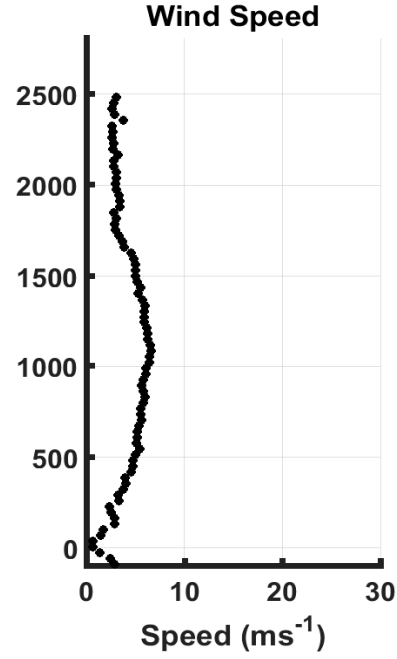

(b)

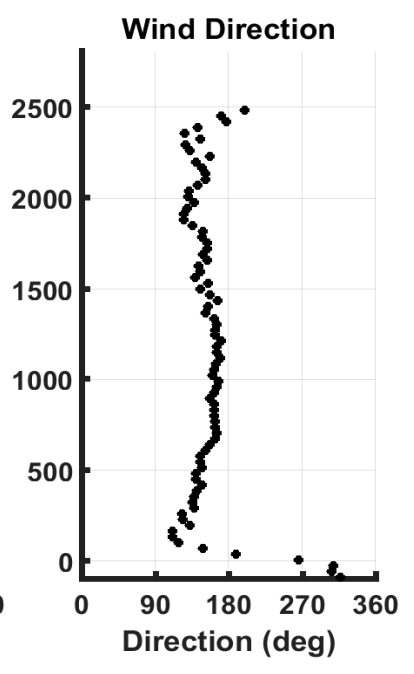

(c)

Figure 7. DAWN profiles of SNR (a), wind speed (b) and wind direction (c) on 1 June 2017 at $171233 Z$ over the Florida peninsula.

\subsubsection{Vertical Profile Comparisons with Dropsondes}

During CPEX, measurements of the vertical profile of winds were also obtained from the YES HDSS/XDD dropsondes launched from the DC-8 during all missions The XDDs and the HDSS system were previously used during the 2015 Tropical Cyclone Intensity (TCI) experiment [23,24] and the 2015 Polar Winds II campaign $[17,18]$, and provide a good source of comparison or validation for the DAWN wind profiles.

The XDDs (referred to as "dropsondes" for the rest of this discussion) provided wind measurements at a 4-Hz rate from aircraft flight level down to $\sim 25-50 \mathrm{~m}$ above the surface. Over 300 dropsondes were attempted during CPEX with between 10 and 31 launches during each individual mission when the DAWN was operating. In total, there were 279 dropsondes that were successful and provided measurements in the vertical column. Figures 8 and 9 show examples of DAWN-dropsonde comparisons (neither measurement interpolated to equal levels) for undisturbed and active convection/high cloud conditions. In both cases, at least in a qualitative sense, there is very good agreement by the two different wind measuring systems. However, it should be noted that there are some clear differences, and this is to be expected, especially in and around convection.

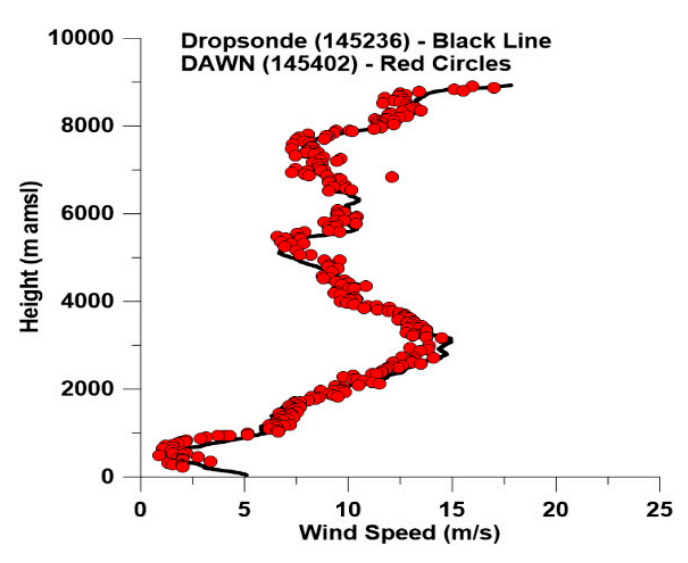

(a)

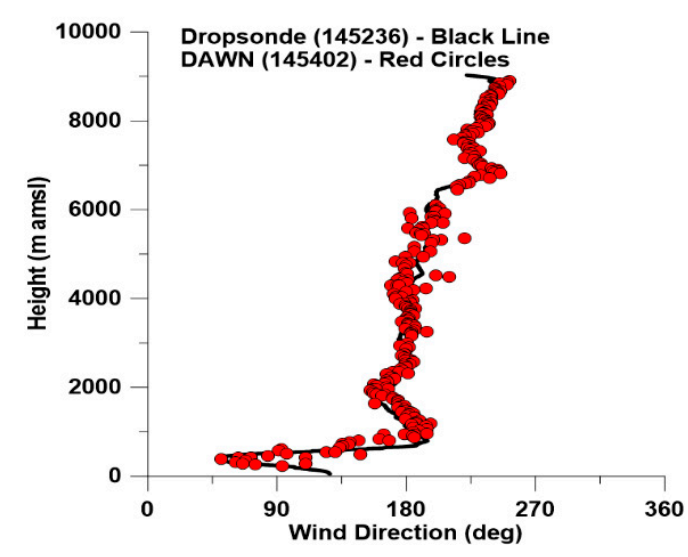

(b)

Figure 8. DAWN-dropsonde comparison of wind speed (a) and wind direction (b) for a convectively undisturbed and convective storm inflow case on 11 June 2017 185300Z. 


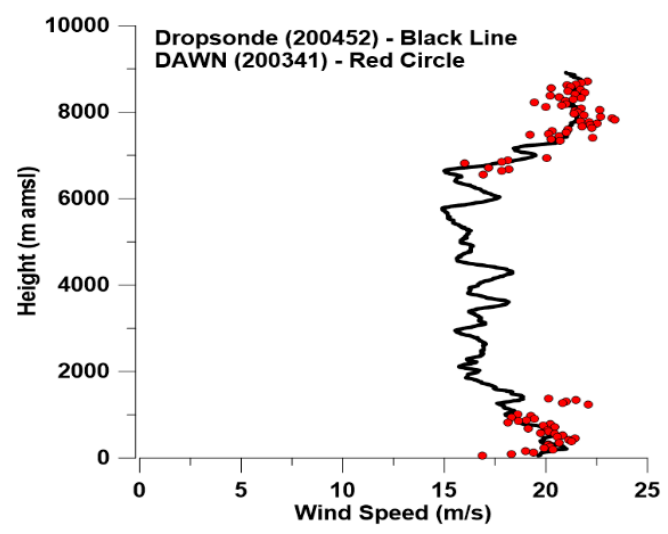

(a)

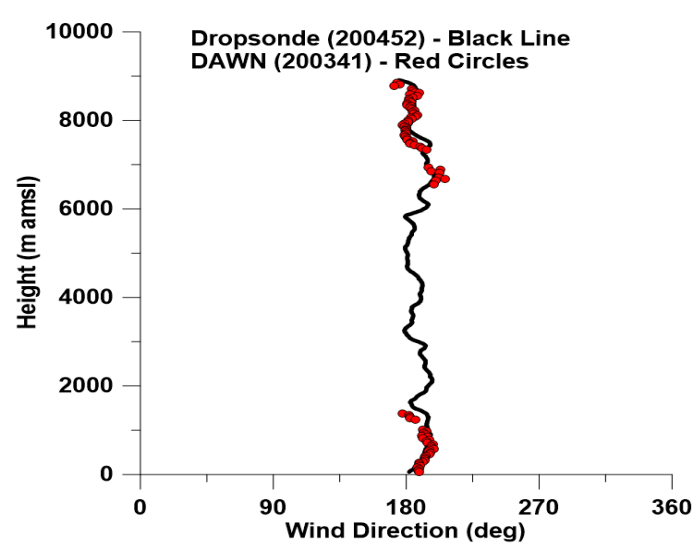

(b)

Figure 9. DAWN-dropsonde comparison of wind speed (a) and wind direction (b) for a convectively active case on 21 June $2017 \sim 200400 Z$.

Depending on the number of scan angles and the integration length chosen for the mission or flight segment, DAWN profiles in most cases are generated as frequently as every 15-20 s (covering a ground track of $\sim 3-4 \mathrm{~km}$ ) or as long as every two minutes and covering a ground track of $12-15 \mathrm{~km}$. On the other hand, the dropsondes fall at a descent rate of between $20-30 \mathrm{~m} / \mathrm{s}$ and can take five minutes to reach the ground depending on the height it was dropped from and can drift up to several $\mathrm{km}$ from the original location of the dropsonde launch.

Statistical comparisons were made between the DAWN wind profile measurements and those from the dropsondes when the dropsondes were successful in obtaining wind data (most cases) and DAWN wind profiles were obtained within two minutes of a successful dropsonde launch and provided vertical coverage over at least a 1-km depth. In total, 162 DAWN-dropsonde comparison pairs were identified and used 16,207 comparison points (i.e., DAWN vertical levels). Included in Table 1 are the daily distribution of the DAWN-dropsonde comparisons throughout the CPEX campaign. It should be noted that no comparisons were done for the data of 17 June and 24 June. The former because there was a shift in the reference frequency in mid-flight that made the DAWN data less reliable for dropsonde comparisons and the latter because, due to weak returns and longer required integration times, the location of successful DAWN profiles and dropsonde locations were too far apart. A "running average" in the vertical of three consecutive data points (33 $\mathrm{m}$ resolution) was used for the DAWN profile measurements and compared with the closest in height dropsonde measurements (which are smoothed within the GPS sensor). In addition, there is also an $~ 1.5 \mathrm{~s}$ delay in the reporting of the dropsonde measurements (Beaubien, private communication) so that a height correction $(\sim 40 \mathrm{~m})$ based on the fall rate was used.

Statistical comparisons were made for the $\mathrm{u}$ - and v-components of the horizontal wind. Figure 10 shows the $\mathrm{u}$ and $\mathrm{v}$ scatter plots for the comparisons between the dropsondes and DAWN for the entire mission. Outliers of greater than $8 \mathrm{~m} / \mathrm{s}$ difference (less than $1.0 \%$ of the total), attributable to one or two of the DAWN observations used in compiling the three-point running average passing the GOF test but providing a "noise" data point, were screened out. Statistics for the $\mathrm{u}$ and $\mathrm{v}$ component comparison for the entire campaign were also broken down into height (Tables 7 and 8) and speed (Tables 9 and 10) sub-categories. In these tables, the comparisons are done for DAWN-dropsondes where mean $\Delta \mathrm{z}$ is the mean absolute height difference between the DAWN and dropsondes observation being compared, the bias is the mean difference of the DAWN and dropsonde component wind speeds $(\Delta \mathrm{u}, \Delta v)$, and the root mean square difference (RMSD) is basically the standard deviation of the differences. 


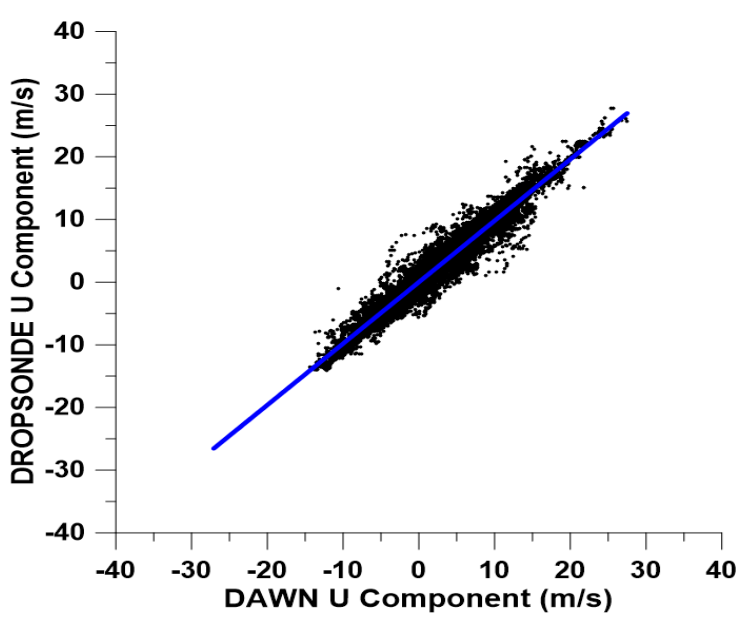

(a)

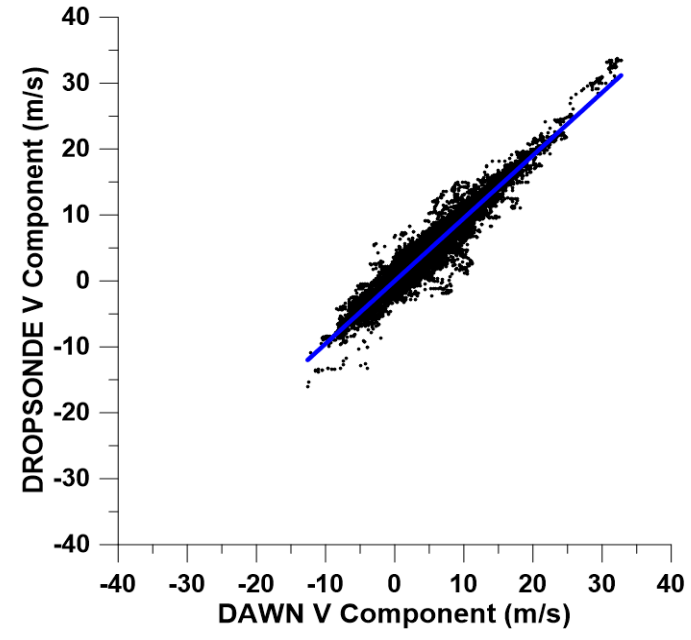

(b)

Figure 10. Scatterplot of DAWN-dropsonde comparison of wind speed (a) and wind direction (b) during CPEX.

Table 7. DAWN-dropsonde comparison statistics by height for $\mathrm{v}$ component of the horizontal wind.

\begin{tabular}{cccccccc}
\hline & $\begin{array}{c}\text { \# of } \\
\text { Comps }\end{array}$ & $\begin{array}{c}\text { Mean } \\
\boldsymbol{\Delta z}(\mathbf{m})\end{array}$ & $\begin{array}{c}\text { Mean } \\
\mathbf{\Delta} \mathbf{v}(\text { bias) }\end{array}$ & $\begin{array}{c}\text { RMSD } \\
\mathbf{\Delta v}\end{array}$ & $\begin{array}{c}\mathbf{R}^{2} \text { Coefficient } \\
\mathbf{Y}=\mathbf{B} \times \mathbf{X}+\mathbf{A}\end{array}$ & $\mathbf{B}$ & $\mathbf{A}$ \\
\hline Sfc-3 km & 4808 & 2.52 & 0.17 & 1.29 & 0.922 & 0.97 & 0.07 \\
\hline $3-6 \mathrm{~km}$ & 1866 & 2.89 & 0.21 & 1.67 & 0.893 & 0.91 & 0.30 \\
\hline $6-9 \mathrm{~km}$ & 6012 & 3.35 & 0.28 & 1.72 & 0.918 & 0.93 & 0.66 \\
\hline $9-12 \mathrm{~km}$ & 3521 & 3.62 & 0.10 & 1.78 & 0.922 & 0.97 & 0.07 \\
\hline ALL & $\mathbf{1 6 , 2 0 7}$ & $\mathbf{3 . 1 1}$ & $\mathbf{0 . 1 9}$ & $\mathbf{1 . 6 1}$ & $\mathbf{0 . 9 2 3}$ & $\mathbf{0 . 9 5}$ & $\mathbf{0 . 0 5}$ \\
\hline
\end{tabular}

Table 8. DAWN-dropsonde comparison statistics by height for u component of the horizontal wind.

\begin{tabular}{cccccccc}
\hline & $\begin{array}{c}\text { \# of } \\
\text { Comps }\end{array}$ & $\begin{array}{c}\text { Mean } \\
\mathbf{\Delta z}(\mathbf{m})\end{array}$ & $\begin{array}{c}\text { Mean } \mathbf{\Delta u} \\
\text { (bias) }\end{array}$ & $\begin{array}{c}\text { RMSD } \\
\mathbf{\Delta u}\end{array}$ & $\begin{array}{c}\mathbf{R}^{\mathbf{2}} \text { Coefficient } \\
\mathbf{Y}=\mathbf{B} \times \mathbf{X}+\mathbf{A}\end{array}$ & $\mathbf{B}$ & $\mathbf{A}$ \\
\hline Sfc-3 km & 4808 & 2.52 & 0.32 & 1.29 & 0.940 & 0.950 & -0.46 \\
\hline $3-6 \mathrm{~km}$ & 1866 & 2.89 & 0.21 & 1.68 & 0.924 & 0.944 & -0.19 \\
\hline $6-9 \mathrm{~km}$ & 6012 & 3.35 & -0.04 & 1.71 & 0.851 & 0.895 & 0.45 \\
\hline $9-12 \mathrm{~km}$ & 3521 & 3.62 & -0.10 & 1.63 & 0.927 & 0.970 & 0.39 \\
\hline ALL & $\mathbf{1 6 , 2 0 7}$ & $\mathbf{3 . 1 1}$ & $\mathbf{0 . 0 8}$ & $\mathbf{1 . 5 9}$ & $\mathbf{0 . 9 4 9}$ & $\mathbf{0 . 9 8 2}$ & $\mathbf{- 0 . 0 3}$ \\
\hline
\end{tabular}

Table 9. DAWN-dropsonde comparison statistics by DAWN wind speed for $\mathrm{v}$ component of the horizontal wind.

\begin{tabular}{cccccccc}
\hline & $\begin{array}{c}\text { \# of } \\
\text { Comps }\end{array}$ & $\begin{array}{c}\text { Mean } \\
\mathbf{\Delta z}(\mathbf{m})\end{array}$ & $\begin{array}{c}\text { Mean } \mathbf{\Delta} \mathbf{v} \\
\text { (bias) }\end{array}$ & $\begin{array}{c}\text { RMSD } \\
\mathbf{\Delta} \mathbf{v}\end{array}$ & $\begin{array}{c}\mathbf{R}^{\mathbf{2}} \text { Coefficient } \\
\mathbf{Y}=\mathbf{B} \times \mathbf{X}+\mathbf{A}\end{array}$ & $\mathbf{B}$ & $\mathbf{A}$ \\
\hline $0-5 \mathrm{~m} / \mathrm{s}$ & 3437 & 2.98 & -0.14 & 1.44 & 0.670 & 0.88 & 0.282 \\
\hline $5-10 \mathrm{~m} / \mathrm{s}$ & 6576 & 3.05 & 0.12 & 1.49 & 0.859 & 0.90 & 0.24 \\
\hline $10-15 \mathrm{~m} / \mathrm{s}$ & 4038 & 3.19 & 0.38 & 1.71 & 0.91 & 0.97 & -0.19 \\
\hline$>15 \mathrm{~m} / \mathrm{s}$ & 2156 & 3.35 & 0.65 & 1.89 & 0.942 & 1.01 & -0.80 \\
\hline $\mathbf{A L L}$ & $\mathbf{1 6 , 2 0 7}$ & $\mathbf{3 . 1 1}$ & $\mathbf{0 . 1 9}$ & $\mathbf{1 . 6 1}$ & $\mathbf{0 . 9 2 3}$ & $\mathbf{0 . 9 5}$ & $\mathbf{0 . 0 4 9}$ \\
\hline
\end{tabular}


Table 10. DAWN-dropsonde comparison statistics by DAWN wind speed for $\mathrm{v}$ component of the horizontal wind.

\begin{tabular}{cccccccc}
\hline & $\begin{array}{c}\text { \# of } \\
\text { Comps }\end{array}$ & $\begin{array}{c}\text { Mean } \\
\boldsymbol{\Delta z} \mathbf{( m )}\end{array}$ & $\begin{array}{c}\text { Mean } \mathbf{\Delta u} \\
\text { (bias) }\end{array}$ & $\begin{array}{c}\text { RMSD } \\
\mathbf{\Delta} \mathbf{u}\end{array}$ & $\begin{array}{c}\mathbf{R}^{2} \text { Coefficient } \\
\mathbf{Y}=\mathbf{B} \times \mathbf{X}+\mathbf{A}\end{array}$ & $\mathbf{B}$ & $\mathbf{A}$ \\
\hline $0-5 \mathrm{~m} / \mathrm{s}$ & 3437 & 2.98 & 0.04 & 1.51 & 0.753 & 1.03 & -0.016 \\
\hline $5-10 \mathrm{~m} / \mathrm{s}$ & 6576 & 3.05 & 0.02 & 1.47 & 0.931 & 0.99 & 0.008 \\
\hline $10-15 \mathrm{~m} / \mathrm{s}$ & 4038 & 3.19 & 0.15 & 1.55 & 0.958 & 0.972 & -0.008 \\
\hline$>15 \mathrm{~m} / \mathrm{s}$ & 2156 & 3.35 & 0.31 & 2.03 & 0.925 & 0.991 & -0.288 \\
\hline $\mathbf{A L L}$ & $\mathbf{1 6 , 2 0 7}$ & $\mathbf{3 . 1 1}$ & $\mathbf{0 . 0 8}$ & $\mathbf{1 . 5 9}$ & $\mathbf{0 . 9 4 9}$ & $\mathbf{0 . 9 8 2}$ & $\mathbf{- 0 . 0 3}$ \\
\hline
\end{tabular}

The statistical comparisons of the DAWN and dropsonde wind measurements show an overall low bias that would be acceptable for model data assimilation (less than $0.5 \mathrm{~m} / \mathrm{s}$ ) with a RMSD of $\sim 1.6$ and $\mathrm{R}^{2}>0.920$ for both components for the data set as a whole. The RMSD is mainly consistent through all the subsets except for the highest wind speeds where it is between 1.8 and 2.1. When broken down into subsets based on DAWN wind speed we do see, as expected, higher RMSD and lower $R^{2}$ in the weaker wind speeds, especially below $5 \mathrm{~m} / \mathrm{s}$. The likely reasons for higher RMSD are the spatial and temporal separations of dropsonde and DAWN samples noted above. The likely primary cause of bias is drift in reported heading from the true heading. As an example, a 0.1-degree heading error on the DC-8 may introduce $0.42 \mathrm{~m} / \mathrm{s}$ error in the computed wind speed along the aircraft ground track. More on the comparisons will be provided in the Discussion section.

\subsubsection{DAWN Comparisons with Flight Level Winds}

The NASA DC-8 is equipped with a GPS/INS that measures flight level wind speed and wind direction at a rate of $1 \mathrm{~Hz}$ throughout the flight while the DAWN wind profiles are computed every 10-120 s depending on the number of shots or integration length chosen for the scanning strategy. In addition, due to the outgoing laser pulse tail backscattering from optics into the detector, we have found that the first "good" measurements from DAWN are not made until 75-90 m below the aircraft. An example comparison is shown in Figure 11. Figure 11 shows a time series by profile number of the wind speed and wind direction obtained from DAWN $100 \mathrm{~m}$ and $200 \mathrm{~m}$ below the aircraft for an 85-profile ( $\sim 40 \mathrm{~min}), \sim 425-\mathrm{km}$ long, and constant level flight segment at $4.5 \mathrm{~km}$ altitude on 20 June 2017. This is qualitatively compared with the co-located and coincident DC-8 flight level winds. In general, there is good agreement especially in wind direction. At times during this flight segment, differences in wind speed are up to $4 \mathrm{~m} / \mathrm{s}$ but it must be remembered that the DAWN profile measurement are representative of a single scan with a volume sampled over $8 \mathrm{~km}$ and one minute while the flight level wind speeds are taken at a single point every second. Additionally, it may also be possible that the DAWN observations provide a calibration of the flight level data winds derived from the DC-8 GPS.

\subsubsection{DAWN Near Surface Wind Comparisons with Dropsondes and Buoys}

During a number of the CPEX missions, DAWN and the DC-8 overflew NOAA National Data Buoy Center (NDBC) buoys in the GoM. At these buoys, wind measurements are provided at a $10 \mathrm{~m}$ altitude [25] every 10-30 min and offer a good comparison for the DAWN and/or dropsonde near-surface observations. For the purposes of comparisons, the last useful value of the dropsondes and DAWN data approaching the surface, usually between 25 and $50 \mathrm{~m}$, are utilized. While the buoy winds have been projected to $10 \mathrm{~m}$, we did not project the dropsonde and DAWN wind observations down to that same level. Rather than introduce wind speed projections from 50 down to $10 \mathrm{~m}$ using the power law or the logarithmic profile, which requires estimates of displacement heights and surface roughness, Table 11 is presented as a "first order" comparison between the three systems and is not an attempt to calibrate or validate any of the three systems. 


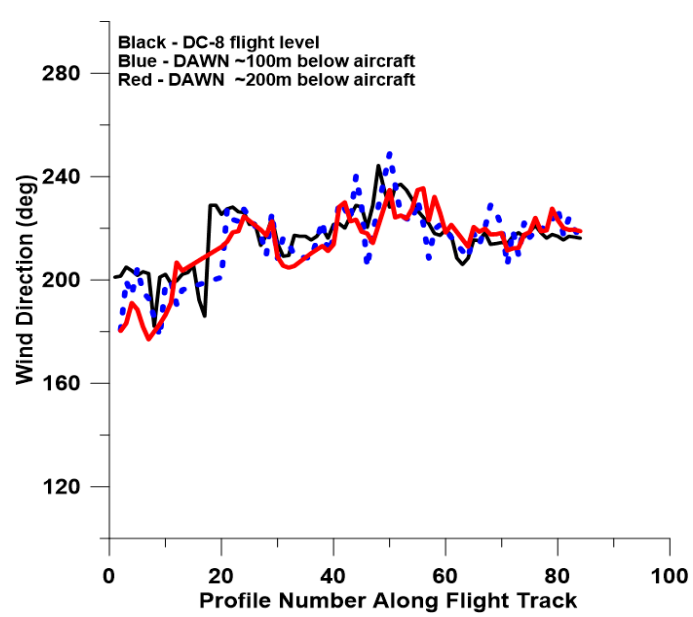

(a)

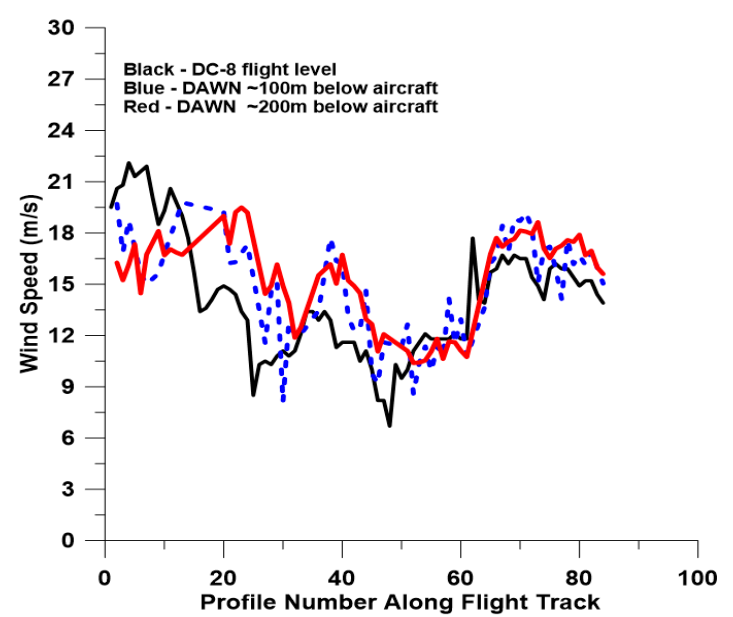

(b)

Figure 11. Wind direction (a) and wind speed (b) for DC-8 flight level observations and DAWN profile observation 100 and $200 \mathrm{~m}$ below the aircraft.

Table 11. Closest to surface observations of wind speed (WS in $\mathrm{m} / \mathrm{s}$ )) and wind direction (WD in deg) for DAWN and dropsondes compared to NDBC buoy measurements at $10 \mathrm{~m}$.

\begin{tabular}{cccccc}
\hline Date/Time & $\begin{array}{c}\text { DAWN-Buoy } \\
\text { Distance }\end{array}$ & Buoy \# & $\begin{array}{c}\text { DAWN } \\
\text { WS/WD }\end{array}$ & $\begin{array}{c}\text { Dropsonde } \\
\text { WS/WD }\end{array}$ & $\begin{array}{c}\text { Buoy } \\
\text { WS/WD }\end{array}$ \\
\hline 0527203018 & Over & 42001 & $5.2 / 125.8(17 \mathrm{~m})$ & $5.1 / 123(24 \mathrm{~m})$ & $3.8 / 144$ \\
\hline 0527210847 & Over & 42001 & $5.7 / 129.7(34 \mathrm{~m})$ & NA & $4.5 / 120$ \\
\hline 0606190855 & $15 \mathrm{~km}$ & 42003 & $7.3 / 263.1(21 \mathrm{~m})$ & NA & $4.1 / 199$ \\
\hline 0616180113 & $2 \mathrm{~km}$ & VCAF1 & $5.7 / 174.0(31 \mathrm{~m})$ & $4.0 / 180(21 \mathrm{~m})$ & $3.7 / 162$ \\
\hline 0620194705 & $19 \mathrm{~km}$ & 42001 & $14.0 / 163.1(13 \mathrm{~m})$ & $13.2 / 160.1(10 \mathrm{~m})$ & $10.9 / 157$ \\
\hline 0620194815 & $21 \mathrm{~km}$ & 42001 & $12.6 / 159.7(13 \mathrm{~m})$ & $13.2 / 160.1(10 \mathrm{~m})$ & $10.9 / 157$ \\
\hline 0620201750 & $15 \mathrm{~km}$ & 42395 & $15,1 / 359.6(15 \mathrm{~m})$ & $9.7 / 008.9(15 \mathrm{~m})$ & $15.1 / 015$ \\
\hline 0621190738 & $45 \mathrm{~km}$ & 42022 & $9.7 / 142.2(16 \mathrm{~m})$ & $11.7 / 143.7(11 \mathrm{~m})$ & $7.8 / 046$ \\
\hline 0621190800 & $\mathrm{NA}$ & 42022 & $7.5 / 119.4(12 \mathrm{~m})$ & $11.7 / 143.7(11 \mathrm{~m})$ & $7.8 / 046$ \\
\hline 0621212017 & $15 \mathrm{~km}$ & 42002 & $12.2 / 292(36 \mathrm{~m})$ & $\mathrm{NA}$ & $10.3 / 287$ \\
\hline 0621221328 & $\mathrm{NA}$ & 42001 & $9.9 / 173.9(39 \mathrm{~m})$ & $11.6 / 173.1(11 \mathrm{~m})$ & $9.3 / 177$ \\
\hline 0621222112 & $8 \mathrm{~km}$ & 42001 & $9.7 / 150.1(36 \mathrm{~m})$ & $6.4 / 165.5(10 \mathrm{~m})$ & $8.9 / 166$ \\
\hline 0621223523 & $3 \mathrm{~km}$ & 42001 & $8.9 / 187.9(18 \mathrm{~m})$ & $11.5 / 167.4(14 \mathrm{~m})$ & $9.1 / 166$ \\
\hline 0621230634 & $15 \mathrm{~km}$ & 42003 & $3.3 / 195.6(26 \mathrm{~m})$ & $11.6 / 143.7(27 \mathrm{~m})$ & $0.8 / 167$ \\
\hline 0624171706 & $8 \mathrm{~km}$ & VCAF1 & $9.6 / 128.0(23 \mathrm{~m})$ & $\mathrm{NA}$ & $3.5 / 110$ \\
\hline 0624171758 & $9 \mathrm{~km}$ & VCAF1 & $4.5 / 121.5(15 \mathrm{~m})$ & $\mathrm{NA}$ & $3.5 / 110$ \\
\hline
\end{tabular}

Table 11 shows the wind speed and wind direction comparison near the surface for DAWN, dropsondes and the buoys during the cases when DAWN and the DC-8 flew over or near the buoy. The heights of the assigned observations for DAWN and dropsondes are also noted. Figure 12 provides scatterplots of DAWN comparisons with buoys and dropsondes for wind speed and wind direction. Despite the temporal averaging and adjusting of buoy wind data to $10 \mathrm{~m}$ [25], the smoothing of dropsonde information (Beaubien, private communication) and issues resolving the ADWL pulse at the ocean surface, the comparisons from a lidar perspective are promising. Ongoing work is focusing on developing processing algorithms to obtain more information in the $0-25 \mathrm{~m}$ above ground level layer and within the wind-induced spray zone. 


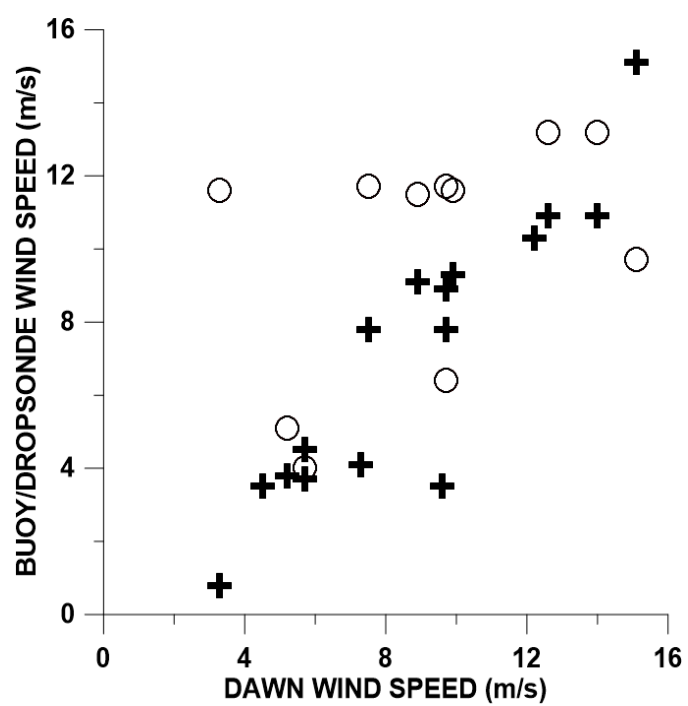

(a)

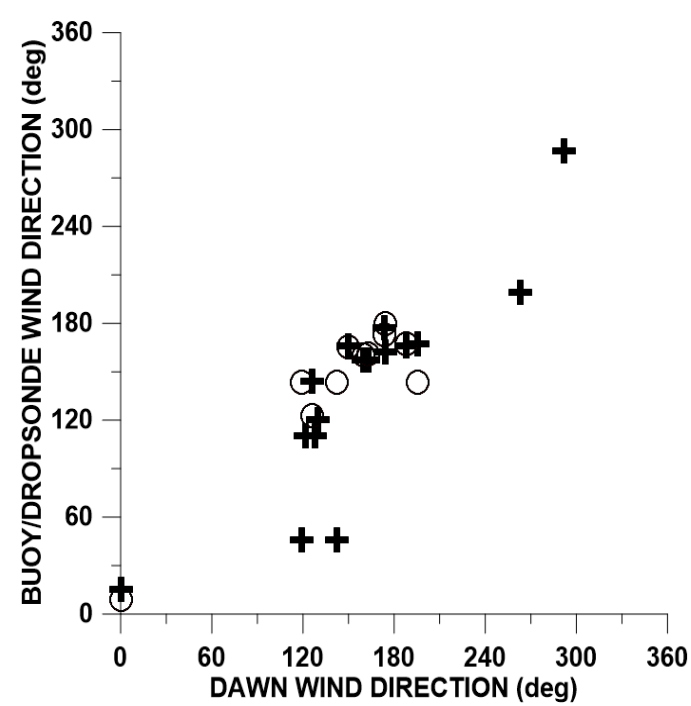

(b)

Figure 12. Scatterplots of the DAWN-buoy $(+)$ and DAWN-dropsonde $(\bigcirc)$ comparisons for wind speed (a) and wind direction (b) during CPEX missions flying over or near NDBC buoys.

\subsection{Case Studies}

Below, we present case studies of the DAWN profile measurements to illustrate the performance, coverage and application of DAWN over different atmospheric environments and under varying convective cloud activity. It should also be mentioned that, during CPEX, there were a number (20) of flight mission "boxes" (see Figure 1) flown to enable the computation of mass budgets and divergence for volumes containing various degrees of cloud coverage to help describe the scale interaction dynamics of the atmosphere over the tropical ocean. Most of the boxes were approximately $100 \times 100 \times 6-10 \mathrm{~km}$ deep and were flown in differing convective conditions including: undisturbed conditions; disorganized or scattered/broken convection; decaying convection and organized (line/area) convective systems.

\subsubsection{Undisturbed Conditions-27 May 2017}

During the 24 May mission, the objective was to utilize DAWN to measure the dynamics of the undisturbed tropical atmosphere over open ocean waters. In particular, to provide measurement that would enable the determination of whether the high vertical and horizontal spacing of the wind measurements would resolve the horizontal mass divergence within an atmospheric volume of $100 \times 100 \times 8 \mathrm{~km}$.

Figure 13 shows the flight track, location of individual DAWN profiles, and instantaneous GOES imagery over the central GoM. On this mission, two complete measurement circuits (Box A and Box B) of a $100 \times 100 \times 8 \mathrm{~km}$ were completed in $40 \mathrm{~min}$ per each box. The resulting time of change of convective cloud conditions over the time taken to acquire the measurements, while not eliminated, is significantly reduced from previous attempts at estimating the convective-mesoscale divergence and vertical velocity of an active convective region.

Flying at an altitude of slightly below $8 \mathrm{~km}$, DAWN profiles were obtained every $5 \mathrm{~km}$ in the horizontal with 18-19 good profiles per leg. Figures 14 and 15 show $x-Z$ plots or curtains of wind speed and wind direction for the DAWN base processing over Box A starting from the southeast corner and going westward. The total column gaps are where the DC- 8 was making the turns in the budget box and profiles were not included because the roll angles surpassed the threshold ( 2.5 degrees) mentioned in Section 4.1. We have compared wind vector retrievals within turns with those just before and after turns of the CPEX boxes and have decided not to put that data into the archives for modelers and 
process investigators until the processing and issues (i.e., height assignments near the surface) have been resolved.

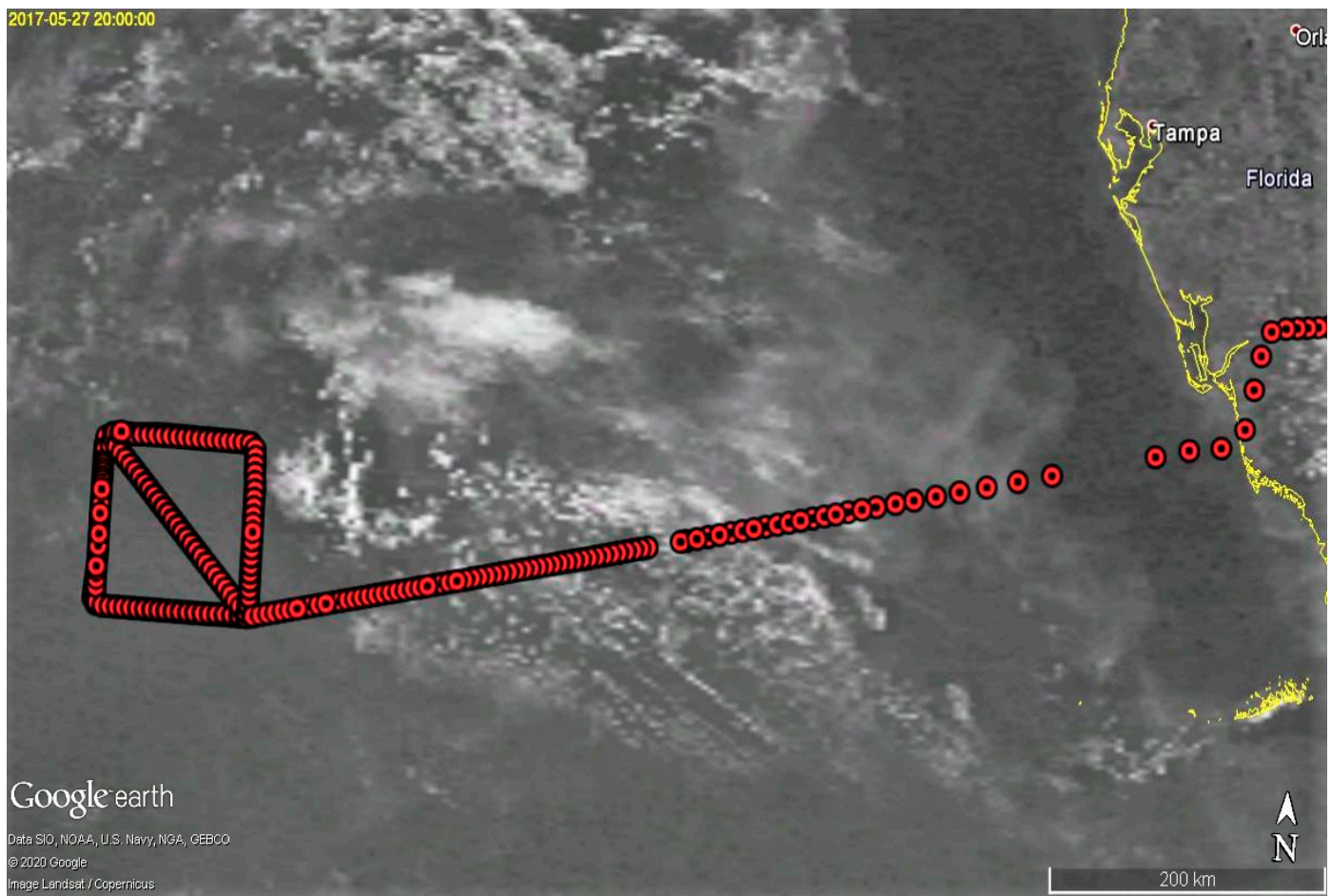

Figure 13. DC- 8 and DAWN flight track over budget box in central GoM on 27 May 2017 with GOES-13 VIS imagery at $2000 \mathrm{Z}$ (the beginning of the first box) (Google Earth).

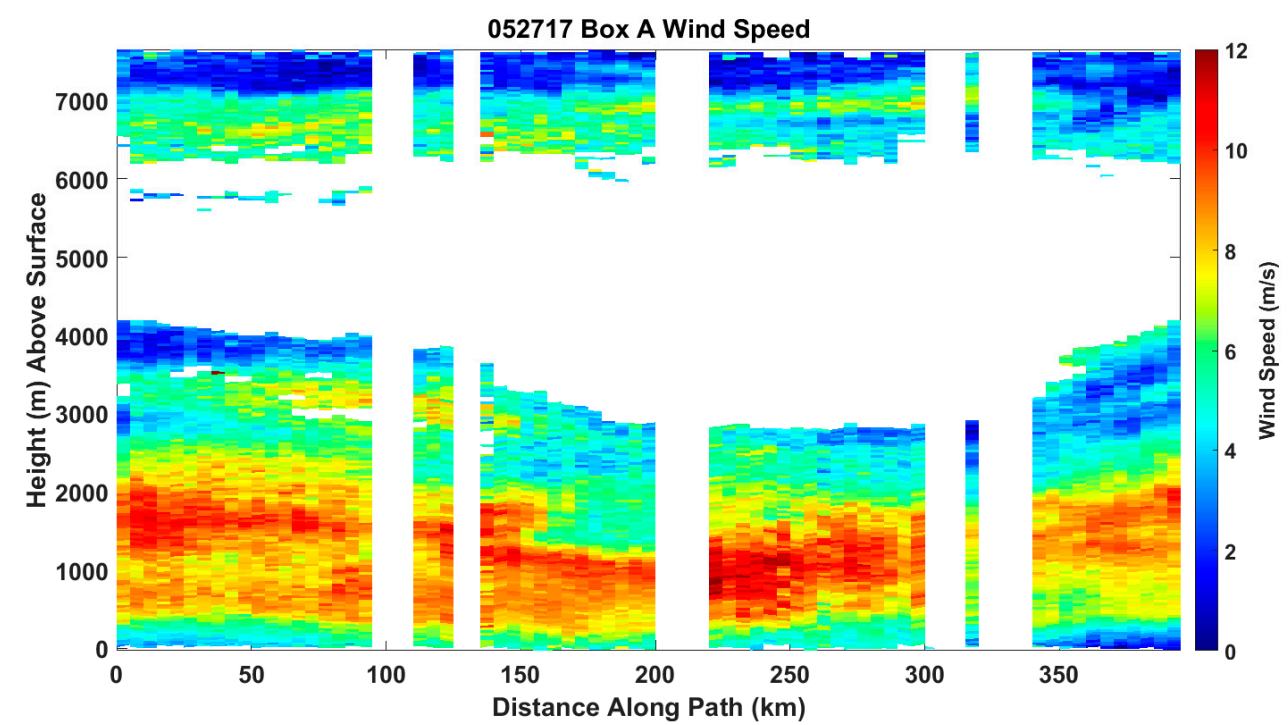

Figure 14. Curtain of DAWN wind speed profiles around Box A between 200005Z and 205006Z on 27 May 2017.

Other than a gap between 3 and $6 \mathrm{~km}$ altitude caused by weak signal/low aerosol return, full base $(33 \mathrm{~m})$ wind profiles up to $7.5 \mathrm{~km}$ were obtained during this mission. However, as can be seen by Figure 16 which was taken at the midpoint of the western S-N leg of Box A, the ASIA advanced processing fills in this low signal/low aerosol gap. This was true for almost all the profiles during this focused part of the 27 May flight. 


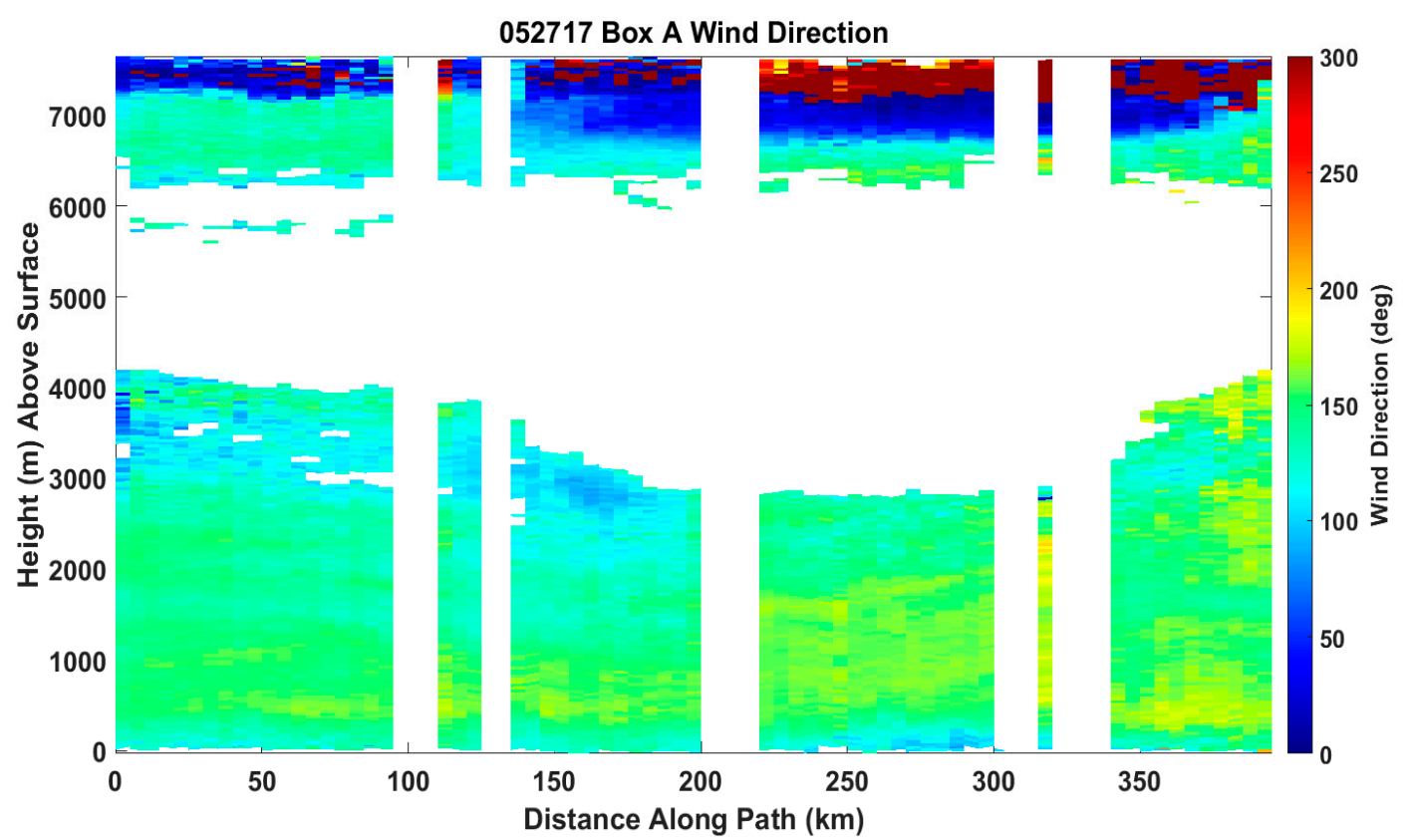

Figure 15. Curtain of DAWN wind direction profiles around Box A between 200005Z and 205006Z on 27 May 2017.

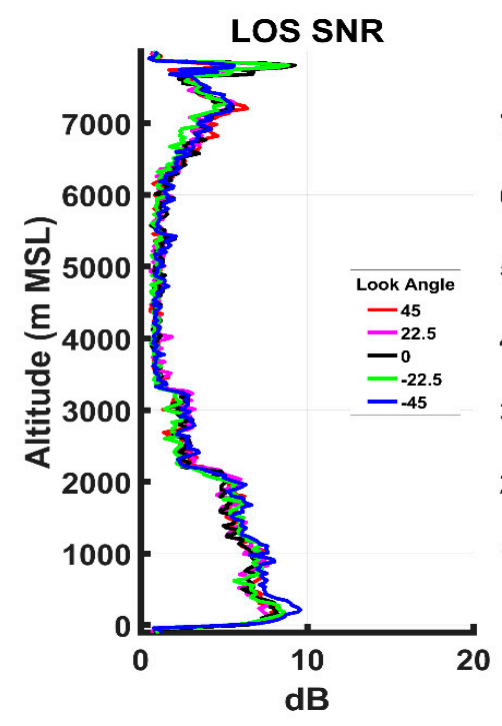

(a)

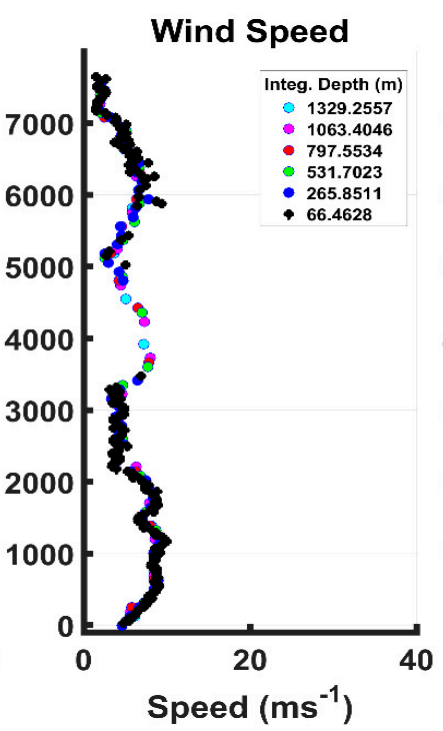

(b)

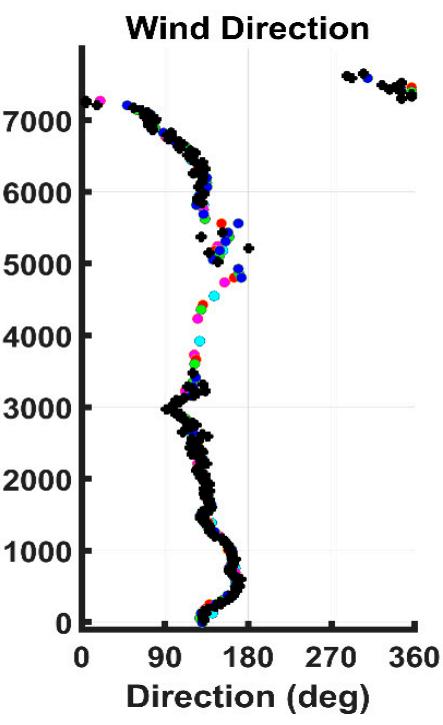

(c)

Figure 16. DAWN vertical profiles of SNR (a), wind speed (b) and wind direction (c) for the mid point of the western S-N leg of 27 May 2017 Box A at 202220Z.

Figure 17 shows the divergence computed over the atmospheric volumes of Box A and Box B. Both volumes display small values of divergence of both signs with positive divergence dominating in the lower (0-2000 m), middle (3000-5000 m) and higher layers (6000-7000 m), none exceeding $5 \times 10^{-5} \mathrm{sec}^{-1}$. Only extremely small values of convergence (maximum $-2 \times 10^{-5}$ ) are measured in the mid-levels $(2500 \mathrm{~m}$ and $5000 \mathrm{~m}$ ). The divergence structure of the two volumes are coherent and consistent with clear skies and lack of convective cloud. Absence of shear is also consistent with the chance of convective cloud [26]. Work will progress in examining progressively structured divergence fields associated with corresponding convection. These initial results suggest that DAWN has the potential to provide insight into subtle organization of the mass field in the initiation and organization of deep convection where these processes over the open tropical ocean are expected to be difficult to detect. 


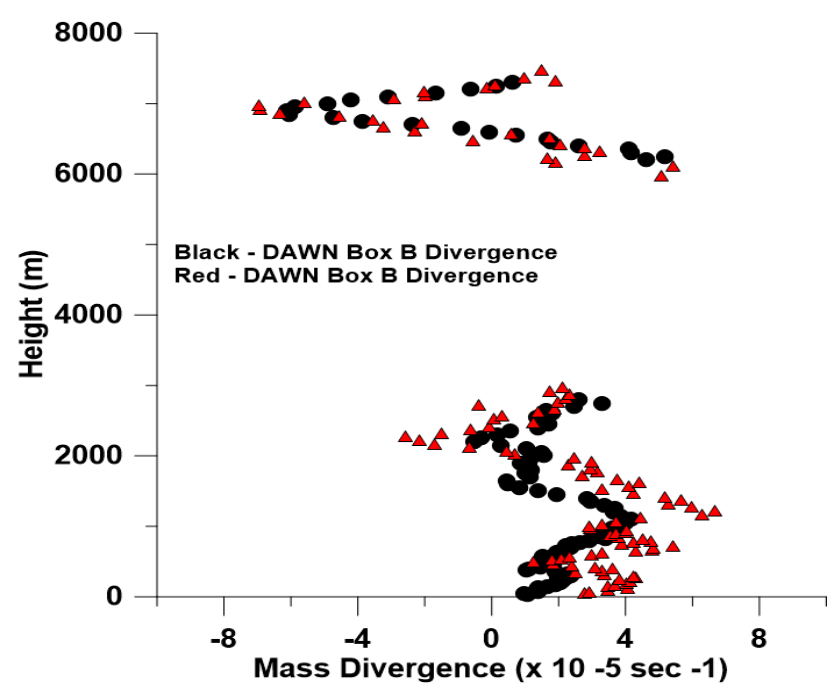

Figure 17. Mass divergence computed over Box A and Box B during 27 May 2017.

\subsubsection{Investigation of Tropical Storm Cindy-21 June 2017}

On 21 June 2017, the DC-8 and DAWN investigated the environment and circulation center of TS Cindy in the northern GoM. Figure 18 shows the flight track, location of individual DAWN profiles, and instantaneous GOES imagery over the northern GoM on this day. During this mission, DAWN profiles were attempted and obtained below the flight level of 9-11 km near the center of TS Cindy and at $4 \mathrm{~km}$ to investigate the PBL in the southern inflow region. Figures 19 and 20 show the DAWN profiles that were obtained to the NW of the center of TS Cindy and near the active convection. Despite the presence of clouds (as noted by the SNR returns and satellite imagery) to the northwest of the center, although not able to make full profile measurements, DAWN was able to provide useful measurements in several layers of the column.

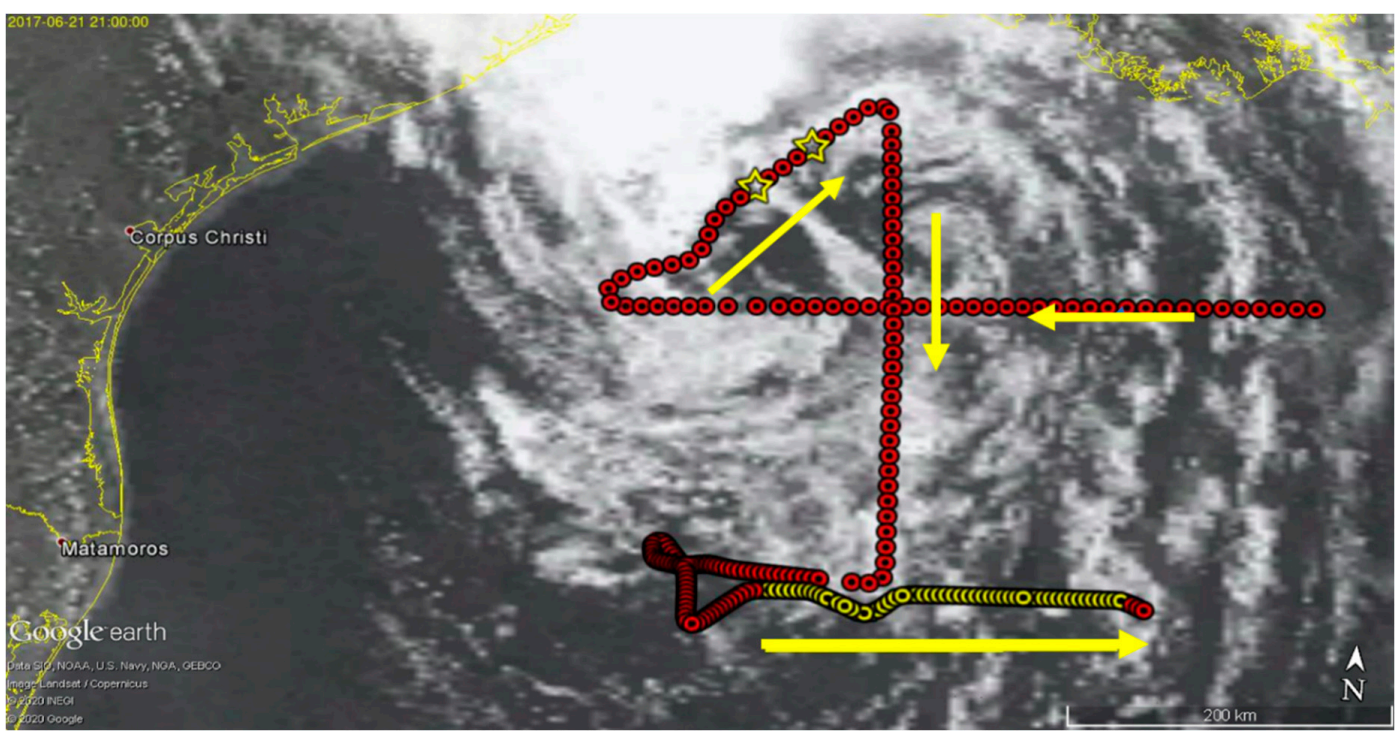

Figure 18. DC-8 and DAWN flight track investigating TS Cindy on 21 June 2017 with GOES13 VIS imagery at $2100 \mathrm{Z}$ along with the location of the selected profiles (gold star) to the NW and the series of profiles (yellow line) to the south of the center (Google Earth). 


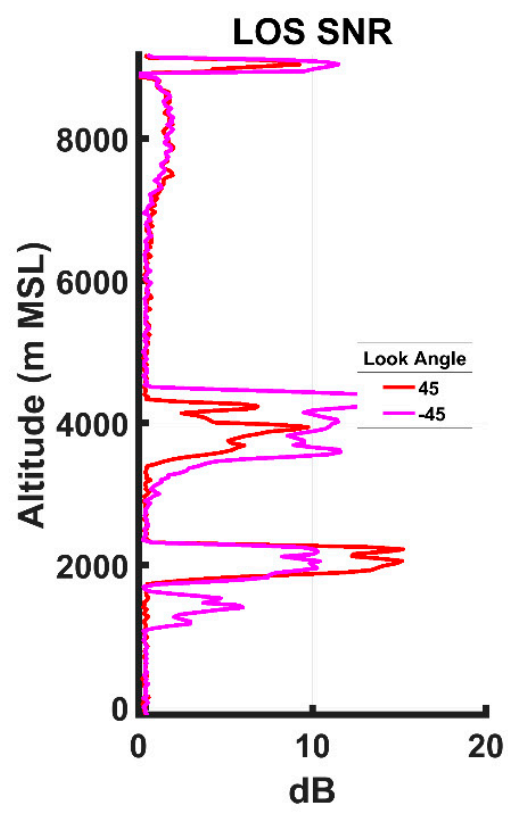

(a)

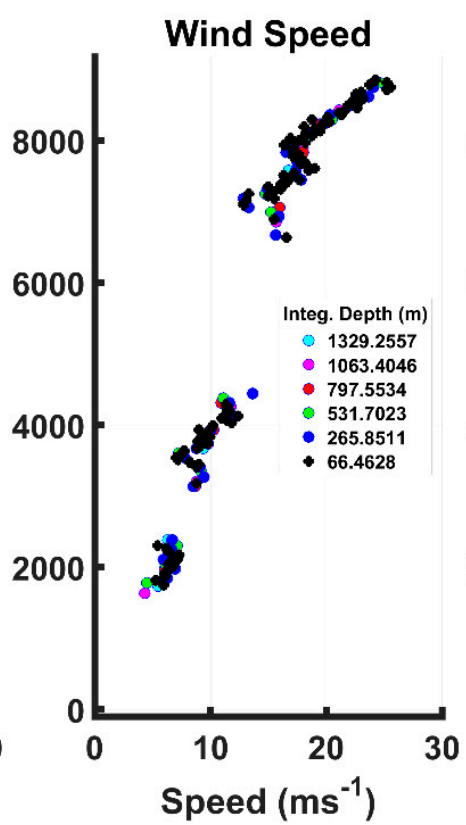

(b)

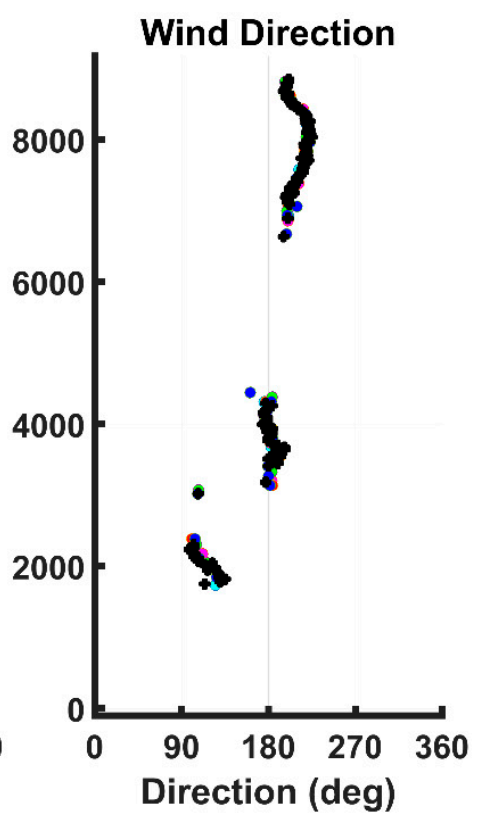

(c)

Figure 19. DAWN vertical profiles of SNR (a), wind speed (b) and wind direction (c) NW of the center of TS Cindy at $203415 Z$ on 21 June 2017.

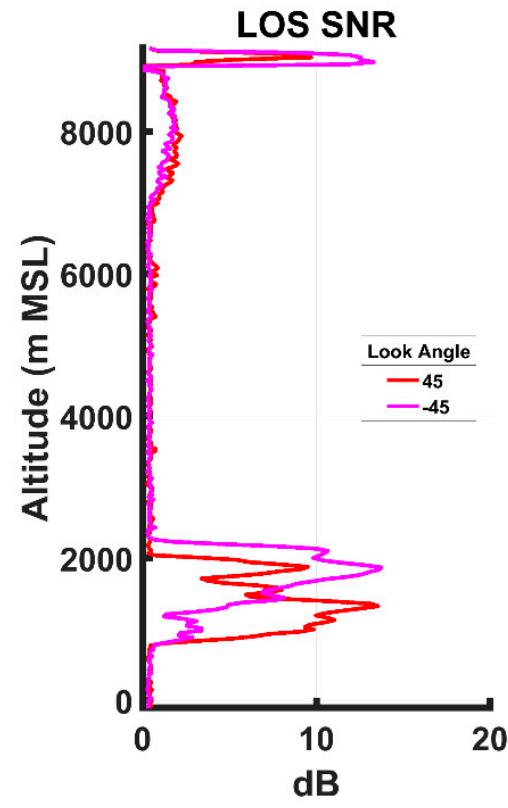

(a)

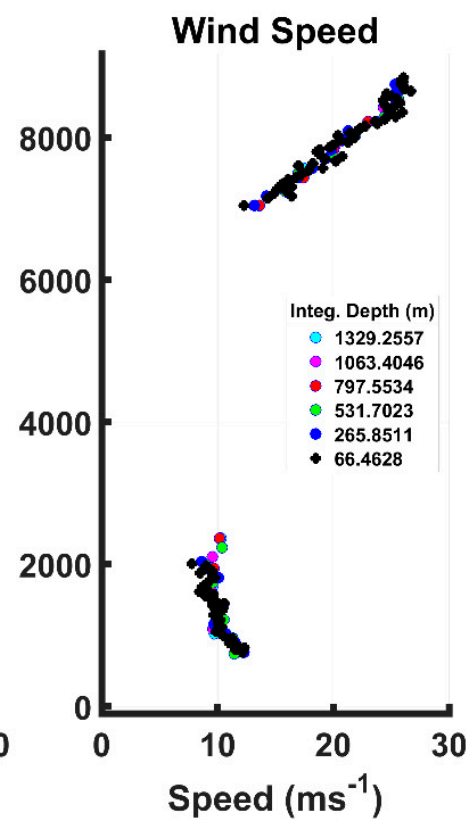

(b)

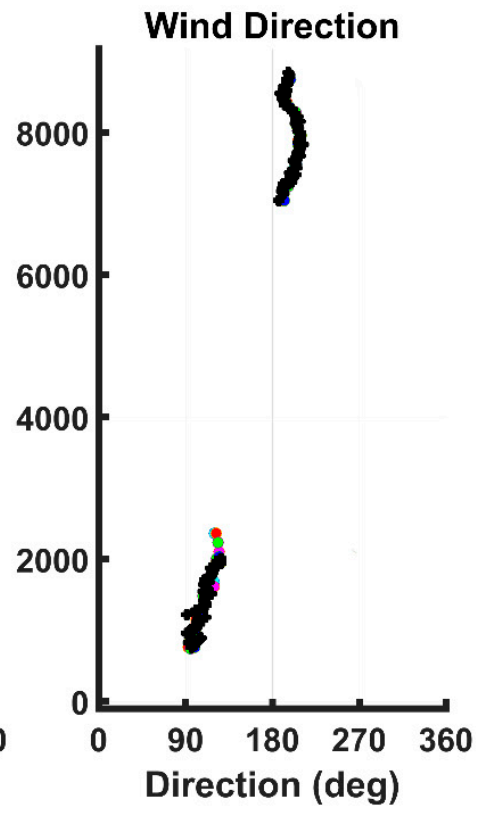

(c)

Figure 20. DAWN vertical profiles of SNR (a), wind speed (b) and wind direction (c) NW of the center of TS Cindy at $203740 \mathrm{Z}$ on 21 June 2017.

Towards the end of the 21 June mission, the aircraft flew at $4 \mathrm{~km}$ to investigate the deep low-level circulation to the south of the center of TS Cindy to take profiles measurements every $\sim 4 \mathrm{~km}$. Figures 21 and 22 show curtains of wind speed and wind direction between the surface and $4 \mathrm{~km}$ obtained on this flight. As mentioned and explained in Sections 4.1 and 4.3.1, the full column gaps are a result of no profile measurement provided when there was excessive roll or heading change. Still, these profiles highlight the ability of DAWN to make high resolution profiles measurements in the environment of a tropical system. The attenuated profiles also illustrate how clouds can confound the ADWL. 
The profiles presented in Figures 19-22 were also assimilated into the Univ. of Utah WRF model and showed a positive impact in the forecast of TS Cindy [10].

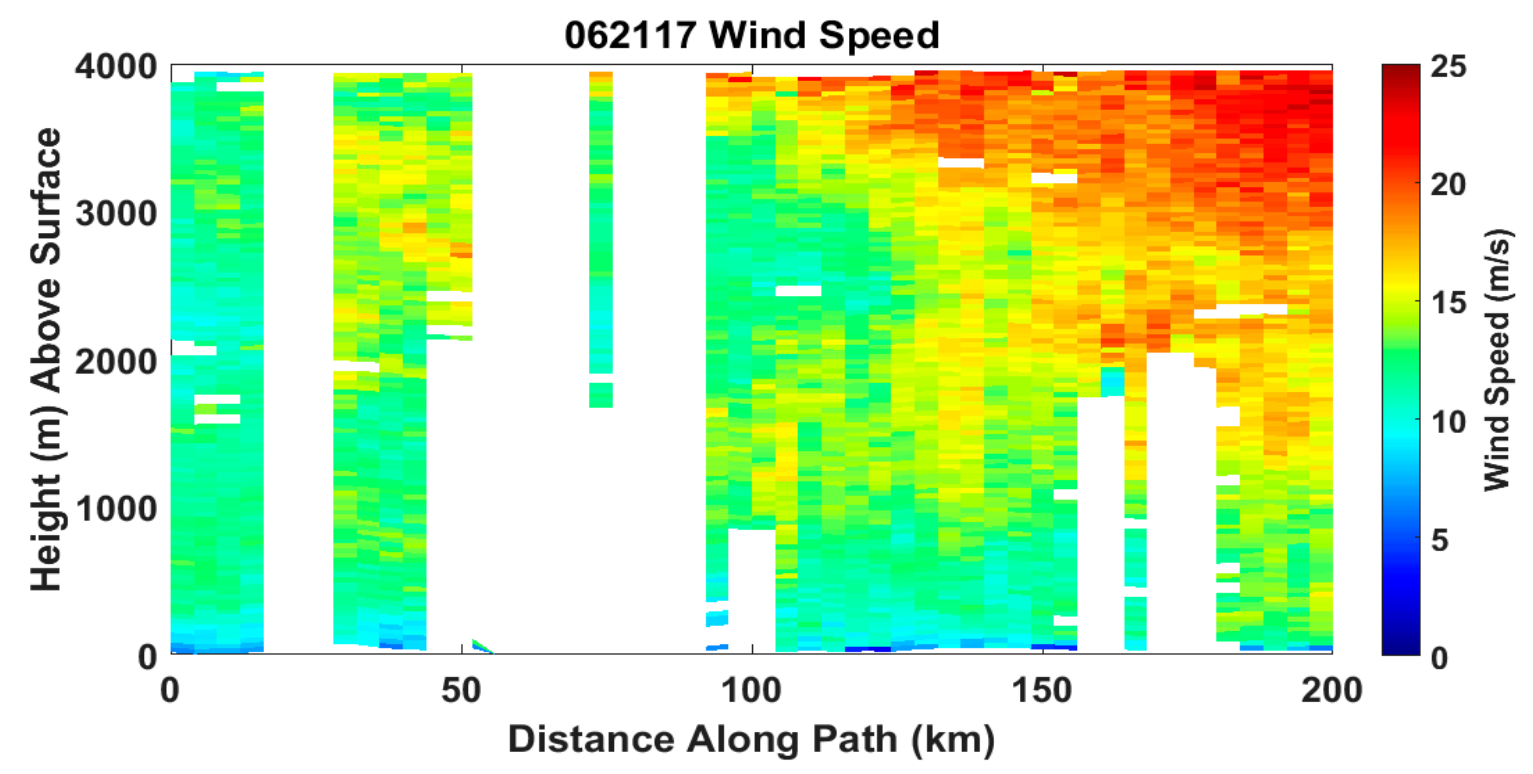

Figure 21. Curtain of DAWN wind speed profiles south of TS Cindy Center between $213855 Z$ and $215839 Z$ on 21 June 2017.

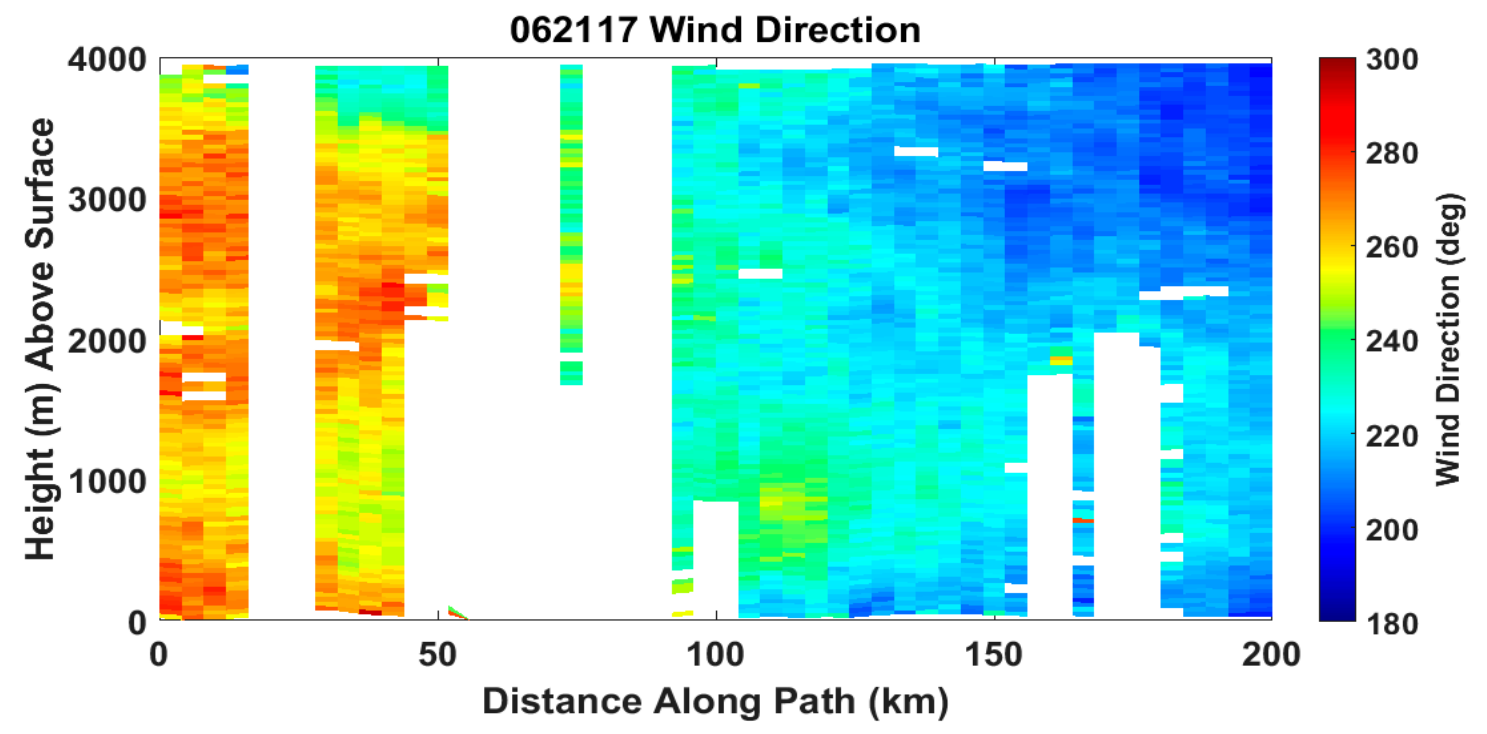

Figure 22. Curtain of DAWN wind direction profiles south of TS Cindy Center between $213855 \mathrm{Z}$ and $215839 Z$ on 21 June 2017.

\subsubsection{Organized Convection and Inflow-11 June 2017}

On 11 June 2017, the DC-8 and DAWN were flown to investigate both the inflow and active convection of an organized convective system in the central GoM. Figure 23 shows the flight track, location of individual DAWN profiles, and instantaneous satellite imagery over the central GoM on this day. During this mission, DAWN profiles were attempted and obtained below the flight level of 9-9.5 km with a horizontal resolution of 8-10 km. Figures 24-26 show the wind profiles obtained in the southern inflow region of the convection moving west to east from relatively undisturbed to the increased cloudiness and active convection. Full profiles up to $9 \mathrm{~km}$ were obtained in the clearer inflow region and illustrate the sheared low-level flow. As the DC-8 moved into the active convection, although clouds prevented measurements in the lower portions of the column, important 
measurements were also obtained between 7 and $9 \mathrm{~km}$. These profiles were also used by Turk et al. [12], who showed the positive impact of using DAWN winds together with winds obtained from the APR-2 in the convective regions for both analysis and numerical modeling.

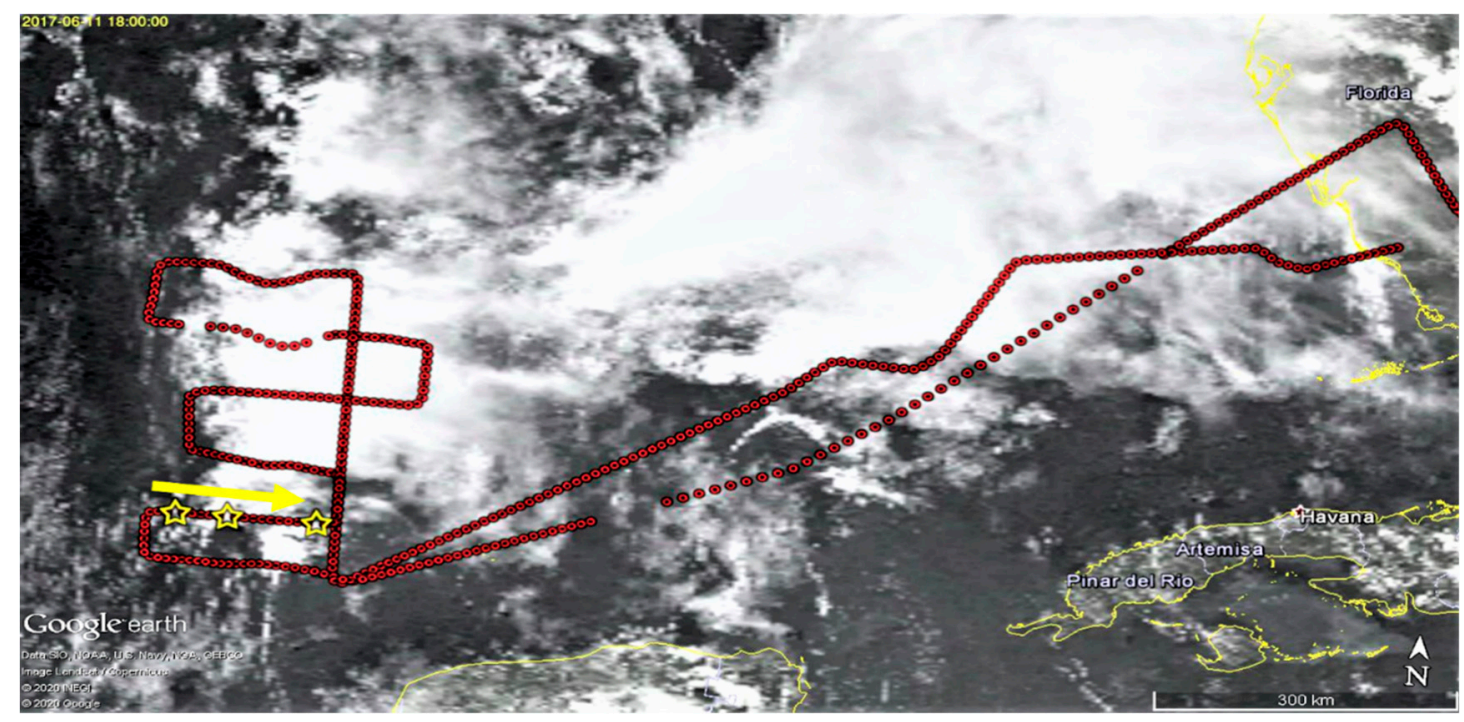

Figure 23. DC-8 and DAWN flight track investigating organized convection on 11 June 2017 with GOES13 VIS imagery at 1800Z near the time of the selected profiles (gold star) in the inflow region (Google Earth).

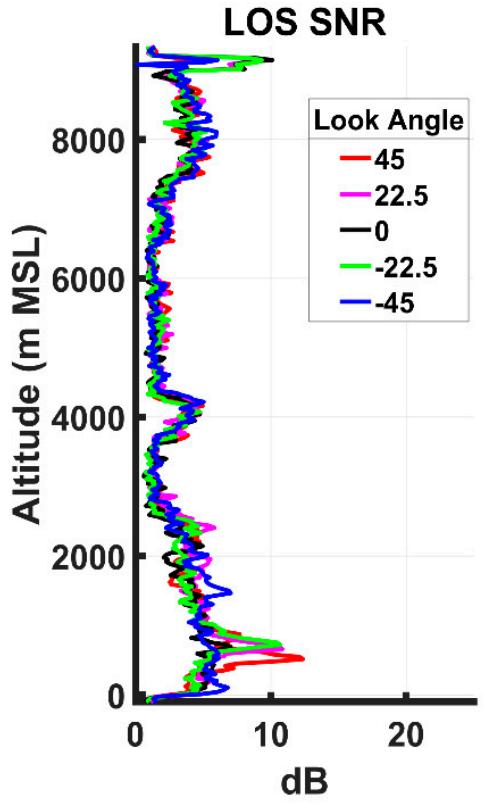

(a)

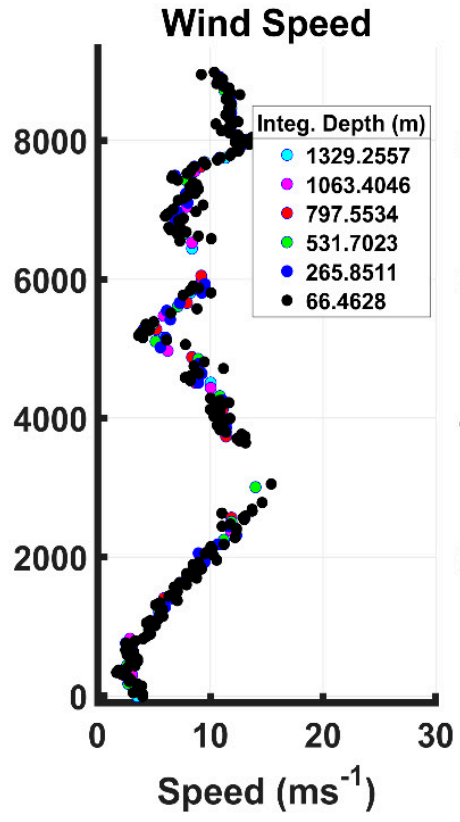

(b)

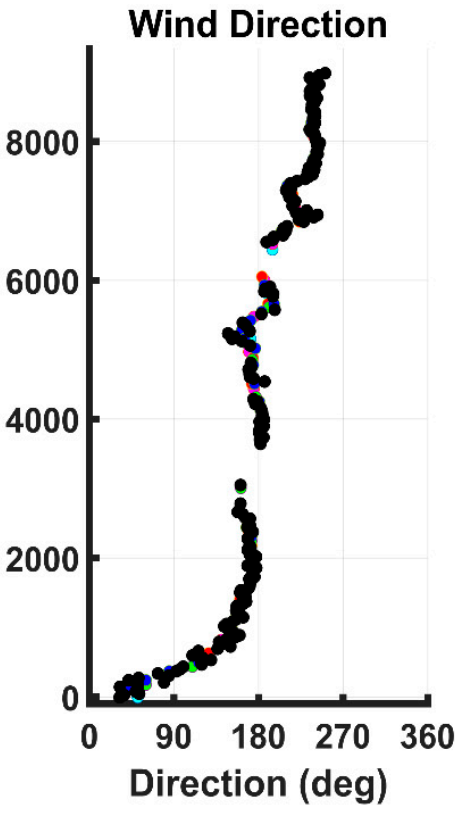

(c)

Figure 24. DAWN vertical profiles of SNR (a), wind speed (b) and wind direction (c) in inflow region of convection at $182117 \mathrm{Z}$ on 11 June 2017. 


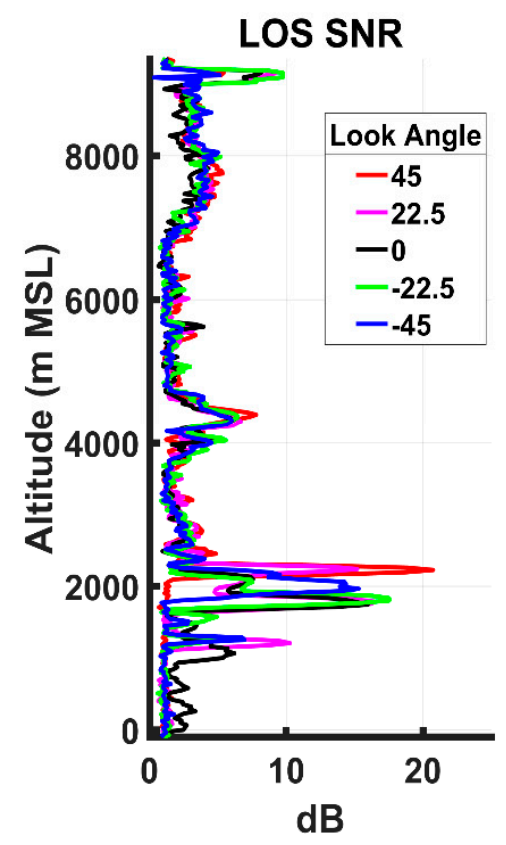

(a)

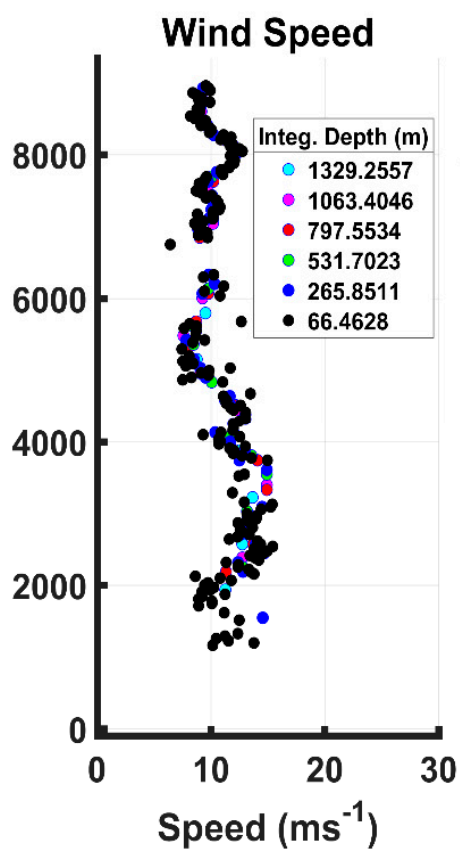

(b)

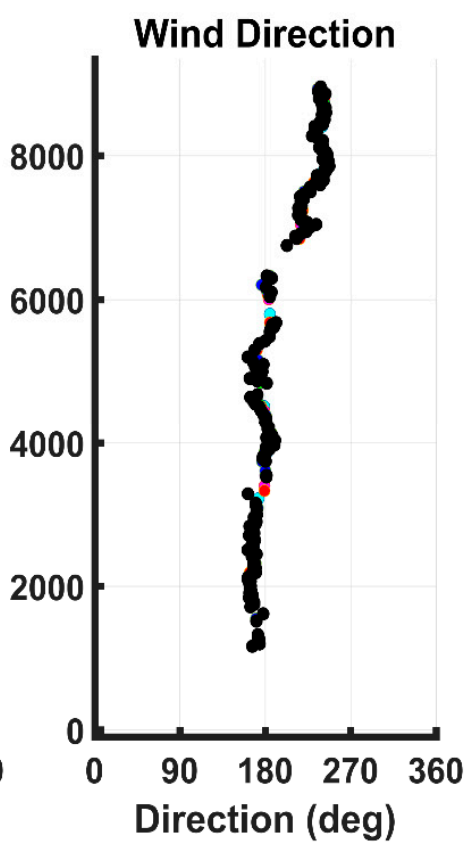

(c)

Figure 25. DAWN vertical profiles of SNR (a), wind speed (b) and wind direction (c) in inflow region of convection at $182534 \mathrm{Z}$ on 11 June 2017.

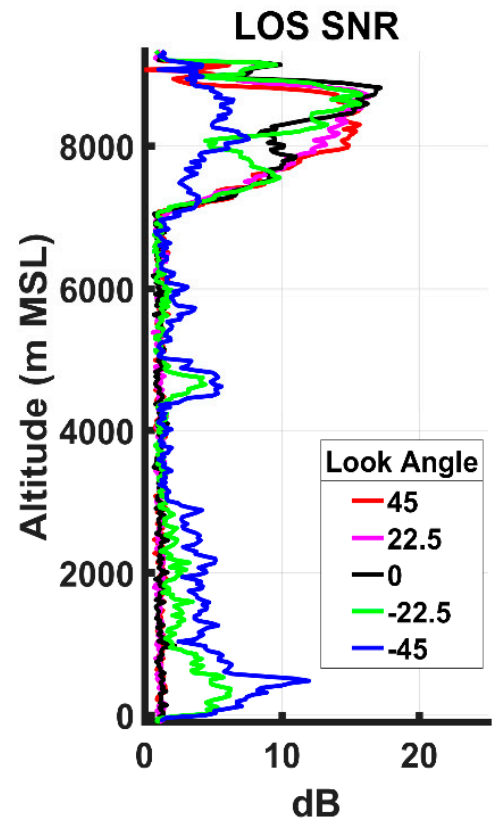

(a)

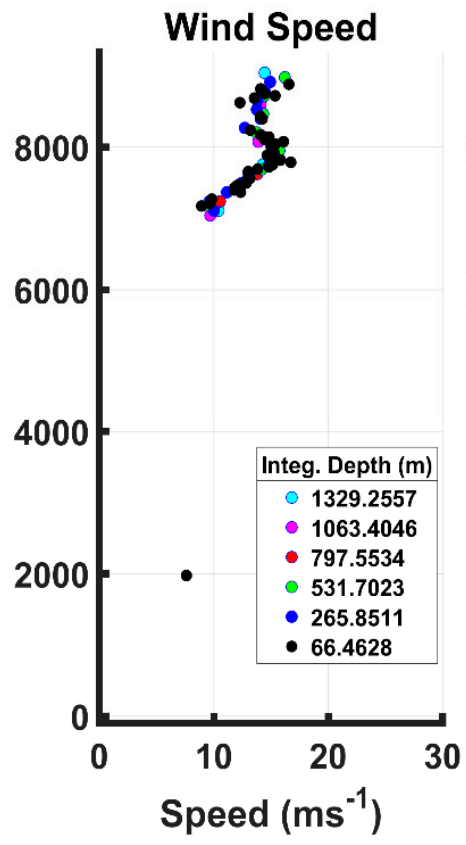

(b)

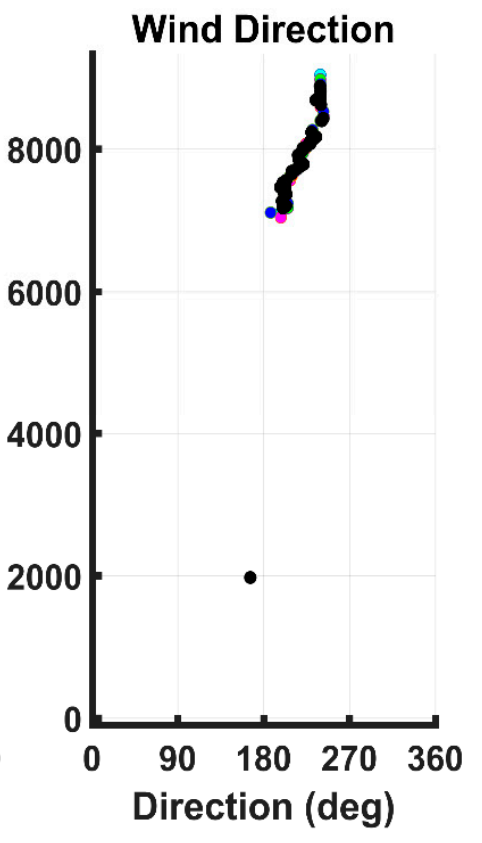

(c)

Figure 26. DAWN vertical profiles of SNR (a), wind speed (b) and wind direction (c) in convective region at $183532 Z$ on 11 June 2017.

\section{Discussion}

Throughout the DAWN comparisons with the more traditional dropsondes, as well as with flight level winds and near surface buoy winds, there has been no mention of "errors". Each of these observing systems measures on differing time and space scales. The lack of truth or calibration-quality wind data above ground-based tower heights or even ground based lidars confounds any effort to 
assess the accuracy of either point measurements or volume-sampled measurements via observation comparisons. By analogy, an ADWL is to a tower mounted anemometer as a precipitation radar is to a ground-based rain gauge.

The wind vector observation comparisons presented here demonstrate that platform motion, pointing knowledge offsets, laser frequency jitter and aerosol backscatter variability can all be accounted for to a level of certainty that results in very low bias for wind speed measurements and very reasonable RMSD values when the differing means of measurement are considered. The message here is that a coherent technology ADWL can deliver to the atmospheric research and operational forecasting communities a low bias, accurate wind profile from $10+\mathrm{km}$ altitude with a high vertical resolution ( $30 \mathrm{~m})$ every $2-10 \mathrm{~km}$ along the ground track, aerosols and clouds permitting.

The fidelity and density of ADWL wind observations is a significant improvement over dropsonde sampling with 50-100 km spacing. However, as is the case in most research projects such as CPEX, it is the mix of instrumentation that determines the success of confirming and discovering physical and dynamic relationships critical to understanding and parameterizing atmospheric (and air/sea interactions for MABL investigations) processes needed to advance numerical weather and climate change predictions.

Spacing between profiles will also increase with faster scanner movement between azimuths and faster onboard computing, improvements to DAWN already implemented at LaRC in preparation for the planned NASA CPEX-Aerosols and Winds (CPEX-AW) campaign in Cape Verde during July-August 2021. In addition, more gap-free vertical profiles can be achieved with a more powerful ADWL such as the WINDSP $200 \mathrm{~Hz}$ lidar under development at NASA LaRC. While most cloud forms are sufficiently optically thick to obscure profiling within and beneath them, the oversampling with high pulse rates enhances the opportunity of a laser shot to find optically thin "holes" in clouds and obtain wind measurements below the cloud layer. In these instances the bottom of the layer can be sensed, providing cloud physical depths.

The authors also continue to develop advanced means of processing the DAWN data in the lowest $50 \mathrm{~m}$ of the atmosphere with a target of mapping the wind shear over oceans with differing wave states. Within this lower portion of the MABL, we are able to derive metrics related to turbulence and ocean sprays (large and small particles). Future DAWN based research includes expanded numerical model assimilation of DAWN data (with Zhaoxia Pu of the University of Utah) as well as creating data and signal processing algorithms to obtain higher vertical resolution in the MABL than is currently archived.

\section{Conclusions}

While NASA's CPEX field campaign in 2017 was primarily designed to study tropical convective processes, it was also designed to feature and evaluate the performance of the DAWN lidar operating from high altitude $(\sim 10-12 \mathrm{~km})$ on a fast moving aircraft $(\sim 225 \mathrm{~m} / \mathrm{s}$ ground speed $)$ in weather conditions ranging from undisturbed cloud free to deep convection associated with a tropical cyclone. In this paper, we have summarized the steps taken, and the challenges faced, in the processing of the raw DAWN data (signal return) into LOS and wind profile products and evaluated the performance of DAWN in terms of measurement bias and general statistical differences with the other sources of wind observations.

During more than $80 \mathrm{~h}$ of flight, there were over 160 cases where there were successful, co-located and coincident profiles from both DAWN and the dropsondes that could be used in comparisons. The statistical comparisons of the DAWN and dropsonde wind measurements show an overall low bias that would be acceptable for model data assimilation (less than $0.5 \mathrm{~m} / \mathrm{s}$ ) with a RMSD of $\sim 1.6$ and $\mathrm{R}^{2}>0.920$ for both components for the data set as a whole. From the CPEX experience, we conclude that the DAWN wind profiles are of high precision, $\sim 30 \mathrm{~m}$ vertical resolution and with horizontal spacing as fine as $3-7 \mathrm{~km}$ on the NASA DC-8 (with potential for 1-2 km on the NASA P3 given its slower airspeed) which rival the dropsonde for horizontal wind coverage (aerosols and clouds permitting). 
Case studies were provided which illustrated the benefit of using the DAWN data to investigate and characterize the dynamics of the tropical atmosphere, especially the MABL, over open ocean waters in conditions ranging from undisturbed to active convection. These case studies included the computation of mass divergence within $100 \times 100 \times 10 \mathrm{~km}$ boxed volumes that were often sampled during CPEX. This type of analysis is ongoing with NASA funding to several PIs.

The LOS and wind profile data derived from the DAWN measurements have been archived in NASA/LaRC's ASDC (https://asdc.larc.nasa.gov/) for use by the research communities.

Author Contributions: G.D.E. and M.K oversaw the deployment of DAWN for the CPEX field campaign with M.K. as the Instrument PI and G.D.E. acting as the Science PI for DAWN. G.D.E., S.G., and M.G. participated in the CPEX field campaign, provided meteorological support, and conducted quick-look processing of DAWN data. S.G. and G.D.E. were responsible for software development, final data processing, conducting comparisons with other wind data and the analysis of DAWN data. S.G and G.D.E. were the primary authors of the manuscript but all authors contributed to the discussion and analysis of the results and refinement of the paper. All authors have read and agreed to the published version of the manuscript.

Funding: This research was funded by the United States National Aeronautics and Space Administration (NASA) under contracts NNX17LC85P and NNH17CV05C.

Acknowledgments: We would like to thank the Earth Science Division of NASA's Science Mission Directorate for organizing and conducting the CPEX field campaign, the NASA Earth Science Technology Office for supporting the development of DAWN, and would especially like to acknowledge the NASA LaRC Engineering Directorate for providing and operating DAWN during CPEX. We would also like the thank Mark Beaubien of YES for help with the dropsonde data and processing, and both NASA LaRC's Science Directorate and the CPEX Science Team for their role in CPEX and providing assistance in this effort.

Conflicts of Interest: The authors declare no conflict of interest.

\section{Abbreviations}

The following abbreviations are used in this manuscript:

$\begin{array}{ll}\text { ADWL } & \text { Airborne Doppler Wind Lidar } \\ \text { APR-2 } & \text { Airborne Second Generation Precipitation Radar } \\ \text { ASIA } & \text { Adaptive Sample Integration Algorithm } \\ \text { CPEX } & \text { Convective Processes Experiment } \\ \text { CPEX-AW } & \text { CPEX Aerosols and Winds } \\ \text { DAWN } & \text { Doppler Aerosol WiNd Lidar } \\ \text { FFT } & \text { Fast Fourier Transform } \\ \text { FOM } & \text { Figure Of Merit } \\ \text { FWHM } & \text { Full Width Half Max } \\ \text { GOES } & \text { Geostationary Operational Environmental Satellite } \\ \text { GOF } & \text { Goodness of Fit } \\ \text { GoM } & \text { Gulf of Mexico } \\ \text { GPS } & \text { Global Positioning System } \\ \text { GRIP } & \text { Genesis And Rapid Intensification Processes } \\ \text { HAMSR } & \text { High Altitude MMIC Sounding Radiometer } \\ \text { HDSS } & \text { High Definition Sounding System } \\ \text { HLOS } & \text { Horizontal Line-of-Sight } \\ \text { INS } & \text { Inertial Navigation System } \\ \text { JPL } & \text { Jet Propulsion Laboratory } \\ \text { LaRC } & \text { Langley Research Center } \\ \text { LM } & \text { Levenberg-Marquardt } \\ \text { LOS } & \text { Line-of-Sight } \\ \text { MABL } & \text { Marine Atmospheric Boundary Layer } \\ \text { MASC } & \text { Microwave Atmospheric Sounder for Cubesat } \\ \text { MTHP } & \text { Microwave Temperature and Humidity Profiler } \\ \text { NASA } & \text { National Aeronautics and Space Administration } \\ & \end{array}$




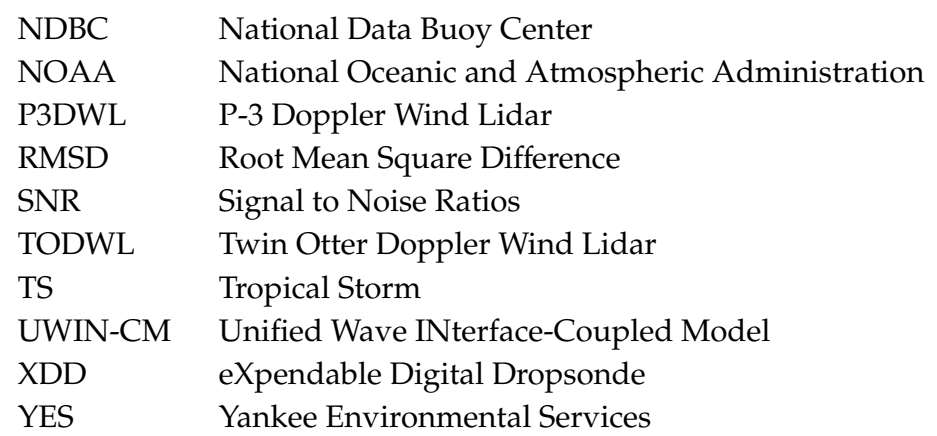

\section{References}

1. Kavaya, M.J.; Beyon, J.Y.; Koch, G.J.; Petros, M.; Petzar, P.J.; Singh, U.N.; Trieu, B.C.; Yu, J. The Doppler Aerosol Wind Lidar (DAWN) Airborne, Wind-Profiling, Coherent-Detection Lidar System: Overview, Flight Results, and Plans. J. Atmos. Ocean. Technol. 2014, 34, 826. [CrossRef]

2. Black, P.; Harrison, L.; Beaubien, M.; Bluth, R.; Woods, R.; Penny, A.; Smith, R.W.; Doyle, J.D. High-definition Sounding System (HDSS) for atmospheric profiling. J. Atmos. Oceanic Technol. 2017, 34, 777-796. [CrossRef]

3. Sadowy, G.A.; Berkun, A.C.; Chun, W.; Im, E.; Durden, S.L. Development of an advanced airborne precipitation radar. Microw. J. 2003, 46, 84-86.

4. Brown, S.T.; Lambrigtsen, B.; Denning, R.F.; Gaier, T.; Kangaslahti, P.; Lim, B.H.; Tanabe, J.M.; Tanner, A.B. The High-Altitude MMIC Sounding Radiometer for the Global Hawk unmanned aerial vehicle: Instrument description and performance. IEEE Trans. Geosci. Remote Sens. 2011, 49, 3291-3301. [CrossRef]

5. Lim, B.; Bendig, R.; Denning, R.; Pandian, P.; Read, W.; Tanner, A. The microwave temperature and humidity profiler instrument airborne shakeout performance. In Proceedings of the 2017 IEEE International Geoscience and Remote Sensing Symposium (IGARSS), Fort Worth, TX, USA, 23-28 July 2017; pp. 4530-4533.

6. Tanelli, S.; Padmanabhan, S.; Peral, E.; Sy, O.; Durden, S.L.; Price, D.; Ortloff, B.; Parashare, C.; Turk, F.J.; Stachnick, R.; et al. Rain Cube and MASC in PECAN; Jet Propulsion Laboratory, California Institute of Technology: Pasadena, CA, USA, 2016.

7. Trier, S.B. Convective Storms/Convective Initiation; Holton, J.R., Ed.; Encyclopedia Atmospheric Sciences Academic Press: London, UK, 2003; pp. 560-570.

8. Pu, Z.; Zhang, L.; Emmitt, G.D. Impact of airborne Doppler wind lidar profiles on numerical simulations of a tropical cyclone. Geophy. Res. Lett. 2010, 37. [CrossRef]

9. Waliser, D.E.; Moncrieff, M.W.; Burridge, D. The "Year" of tropical convective (May 2008-April 2010): Climate variability and weather highlights. Bull. Amer. Meteor. Soc. 2012, 93, 1189-1218. [CrossRef]

10. Cui, Z.; Pu, Z.; Emmitt, G.D.; Greco, S. The Impact of Airborne Doppler Aerosol WiNd lidar (DAWN) Wind Profiles on Numerical Simulations of Tropical Convective Systems during the NASA Convective Processes Experiment (CPEX). J. Atmos. Oceanic Technol. 2020, 37, 705-722. [CrossRef]

11. Turk, J.; Hristova-Veleva, S.M.; Durden, S.; Tanelli, S.; Sy, O.; Emmitt, D.; Greco, S.; Zhang, S. Joint Analysis of Convective Structure from the APR-2 Precipitation Radar and the DAWN Doppler Wind Lidar during the 2017 Convective Processes Experiment (CPEX). Atmos. Meas. Tech. 2020, in press. [CrossRef]

12. Yu, J.; Trieu, B.C.; Modlin, E.A.; Singh, U.N.; Kavaya, M.J.; Chen, S.; Bai, Y.; Petzar, P.J.; Petros, M. 1 J/pulse Q-switched 2-micron solid-state laser. Opt. Letters. 2006, 31, 462. [CrossRef] [PubMed]

13. Singh, U.N.; Walsh, B.M.; Yu, J.; Petros, M.; Kavaya, M.J.; Refaat, T.F.; Barnes, N.P. 20 years of Tm,Ho:YLF and LuLF Laser Development for Global Winds Measurements. Opt. Mater. Express. 2015, 5, 827. [CrossRef]

14. Greco, S.; Emmitt, G.D. Investigation of flows within complex terrain and along coastlines using an airborne Doppler wind lidar: Observations and model comparisons. In Proceedings of the Sixth Conference on Coastal Atmospheric and Oceanic Prediction and Processes, Annual American Meeting Society Conference, San Diego, CA, USA, 25-28 January 2005.

15. Bucci, L.R.; O’Handley, C.; Emmitt, G.D.; Zhang, J.A.; Ryan, K.; Atlas, R. Validation of an Airborne Doppler Wind Lidar in Tropical Cyclones. Sensors 2018, 18, 4288. [CrossRef] [PubMed] 
16. Greco, S.; Emmitt, G.D.; Wood, S.A. Recent Airborne Doppler Wind Lidar Investigations of Lower Troposphere Circulations from the Tropics to the Poles. In Proceedings of the American Meteorology Society 97th Annual Meeting, Observation Symposium Poster Session, Seattle, WA, USA, 22-26 January 2017.

17. Greco, S.; Emmitt, G.D.; Kavaya, M.; Kakar, R.; Cassano, J.J.; Hines, K. Airborne Doppler Wind Lidar Missions in the Arctic: Low Level Observations and Comparison with Models and other Observing Platforms. In Proceedings of the American Meteorology Society 96th Annual Meeting, 20th Conference on Integrated Observing and Assimilation Systems for the Atmosphere, Oceans, and Land Surface (IOAS-AOLS), New Orleans, LA, USA, 10-14 January 2016.

18. DuVivier, A.K.; Cassano, J.J.; Greco, S.; Emmitt, G.D. A case study of observed and modeled barrier flow in the Denmark Strait in May 2015. Mon. Weather Rev. 2017, 145, 2385-2404. [CrossRef]

19. Emmitt, G.D.; Godwin, K.S.; Greco, S.; Wood, S.A. The 2014-2015 Polar Winds DAWN Airborne Campaigns; Instrument Performance, Data Collection and Advanced data Processing Algorithm Development. In Proceedings of the American Meteorology Society 97th Annual Meeting, 8th Symposium on Lidar Atmospheric Applications, Seattle, WA, USA, 16-28 January 2017.

20. Liu, Z.; Kavaya, M.J.; Bedka, K.M. Coherent Doppler Wind Lidar Data Processing Software and Wind Retrieval from the Aeolus Cal/Val Field Campaign. In Proceedings of the ADM-Aeolus CAL/VAL Rehearsal, Météo-France, Toulouse, France, 28-30 March 2019; p. A12A-07.

21. Koch, G.; Beyon, J.Y.; Cowen, L.J.; Kavaya, M.J.; Grant, M.S. Three-dimensional wind profiling of offshore wind energy areas with airborne Doppler lidar. J. Appl. Remote Sens. 2014, 8, 083662.

22. Koch, G.; Beyon, J.Y.; Modlin, E.A.; Petzar, P.J.; Woll, S.; Petros, M.; Yu, J.; Kavaya, M.J. Side-scan Doppler lidar for offshore wind energy applications. J. Appl. Remote Sens. 2012, 6, 063562. [CrossRef]

23. Creasey, R.L.; Elsberry, R.L. Tropical cyclone center positions from sequences of HDSS sondes deployed along high-altitude overpasses. Weather Forecast. 2017, 32, 317-325. [CrossRef]

24. Nelson, T.C.; Harrison, L.; Corbosiero, K.L. Examination of the Expendable Digital Dropsonde-Derived Vertical Velocities from the Tropical Cyclone Intensity (TCI) Experiment. Mon. Weather Rev. 2019, 147, 2367-2386. [CrossRef]

25. Liu, W.T.; Katsaros, K.B.; Businger, J.A. Bulk Parameterizations of Air-Sea Exchanges of Heat and Water Vapor Including Molecular Constraints at the Interface. J. Atmos. Sci. 1979, 36, 1722-1735. [CrossRef]

26. LeMone, M.A.; Zipser, E.J.; Trier, S.B. The role of environmental shear and thermodynamic conditions in determining the structure and evolution of mesoscale convective systems during TOGA COARE. J. Atmos. Sci. 1998, 55, 3493-3518. [CrossRef] 